\title{
Functional characterization of the selective pan-allele anti-SIRPa antibody ADU-1805 that blocks the SIRPa-CD47 innate immune checkpoint
}

Erik Voets ${ }^{1}$, Marc Paradé ${ }^{1}$, David Lutje Hulsik', Sanne Spijkers ${ }^{1}$, Wout Janssen ${ }^{1}$, Joost Rens ${ }^{1}$, Inge Reinieren-Beeren ${ }^{1}$, Gilbert van den Tillaart', Sander van Duijnhoven ${ }^{1}$, Lilian Driessen ${ }^{1}$, Maurice Habraken ${ }^{1}$, Peter van Zandvoort ${ }^{1}$, Joost Kreijtz ${ }^{1}$, Paul Vink', Andrea van Elsas ${ }^{1,2^{*}}$ (D) and Hans van Eenennaam ${ }^{1}$

\section{Abstract}

Background: Accumulating preclinical data indicate that targeting the SIRPa/CD47 axis alone or in combination with existing targeted therapies or immune checkpoint inhibitors enhances tumor rejection. Although several CD47-targeting agents are currently in phase I clinical trials and demonstrate activity in combination therapy, high and frequent dosing was required and safety signals (acute anemia, thrombocytopenia) were recorded frequently as adverse events. Based on the restricted expression pattern of SIRPa we hypothesized that antibodies targeting SIRPa might avoid some of the concerns noted for CD47-targeting agents.

Methods: SIRPa-targeting antibodies were generated and characterized for binding to human SIRPa alleles and blockade of the interaction with CD47. Functional activity was established in vitro using human macrophages or neutrophils co-cultured with human Burkitt's lymphoma cell lines. The effect of SIRPa versus CD47 targeting on human T-cell activation was studied using an allogeneic mixed lymphocyte reaction and a Staphylococcus enterotoxin B-induced T-cell proliferation assay. Potential safety concerns of the selected SIRPa-targeting antibody were addressed in vitro using a hemagglutination assay and a whole blood cytokine release assay, and in vivo in a single-dose toxicity study in cynomolgus monkeys.

Results: The humanized monoclonal IgG2 antibody ADU-1805 binds to all known human SIRPa alleles, showing minimal binding to SIRP $\beta 1$, while cross-reacting with SIRPY, and potently blocking the interaction of SIRPa with CD47. Reduced FcyR binding proved critical to retaining its function towards phagocyte activation. In vitro characterization demonstrated that ADU-1805 promotes macrophage phagocytosis, with similar potency to antiCD47 antibodies, and enhances neutrophil trogocytosis. Unlike CD47-targeting agents, ADU-1805 does not interfere with T-cell activation and is not expected to require frequent and extensive dosing due to the restricted expression of SIRPa to cells of the myeloid lineage. ADU-1805 is cross-reactive to cynomolgus monkey SIRPa and upon singledose intravenous administration in these non-human primates (NHPs) did not show any signs of anemia, thrombocytopenia or other toxicities.

Conclusions: Blocking the SIRPa-CD47 interaction via SIRPa, while similarly efficacious in vitro, differentiates ADU1805 from CD47-targeting agents with respect to safety and absence of inhibition of T-cell activation. The data presented herein support further advancement of ADU-1805 towards clinical development.

Keywords: Cancer immunotherapy, SIRPa, CD47, Innate immune checkpoint, Myeloid cells

\footnotetext{
* Correspondence: AvanElsas@aduro.com

'Aduro Biotech Europe B.V, Oss, The Netherlands

${ }^{2}$ Aduro Biotech, Inc., Berkeley, USA
}

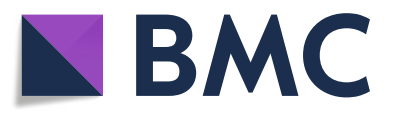

(c) The Author(s). 2019 Open Access This article is distributed under the terms of the Creative Commons Attribution 4.0 International License (http://creativecommons.org/licenses/by/4.0/), which permits unrestricted use, distribution, and reproduction in any medium, provided you give appropriate credit to the original author(s) and the source, provide a link to the Creative Commons license, and indicate if changes were made. The Creative Commons Public Domain Dedication waiver (http://creativecommons.org/publicdomain/zero/1.0/) applies to the data made available in this article, unless otherwise stated. 


\section{Background}

Analogous to the well-established T-cell immune checkpoints (i.e. PD-1, CTLA-4), signal-regulatory protein $\alpha$ $(\mathrm{SIRP} \alpha)$ is regarded as an innate immune checkpoint expressed on dendritic cells, macrophages, monocytes and neutrophils [1]. SIRP $\alpha$ is an inhibitory receptor and member of the so-called paired immune receptor family and has several ligands including the surfactant proteins (e.g. Sp-A and Sp-D) [2], and CD47 [3]. CD47 serves as a "self molecule" signal with its best-characterized functions in the homeostasis of complement- or Igopsonized red blood cells (RBCs) and platelets. Binding of CD47 to SIRP $\alpha$ inhibits phagocytosis of these cells by macrophages thereby preventing their homeostatic clearance $[4,5]$.

The overexpression of CD47 on numerous human cancers [6-11] suggested that tumor cells may evade phagocytosis and clearance by upregulating CD47 expression. Targeting of the SIRP $\alpha / C D 47$ axis in the context of cancer using an anti-CD47 blocking antibody enhanced phagocytosis of acute myeloid leukemia (AML) cells [6]. In addition, targeting the SIRP $\alpha / C D 47$ axis enhances tumor growth inhibition by existing tumor-targeting monoclonal antibody $(\mathrm{mAb})$ therapies (e.g. rituximab, trastuzumab, alemtuzumab, daratumumab and cetuximab) $[8,12-14]$ and synergizes with other treatments including chemotherapy [15], radiotherapy [16], targeted therapy using small-molecule drugs [17] as well as immunotherapeutic agents blocking the PD-1/PD-L1 axis [18, 19].

Numerous agents blocking the SIRP $\alpha-C D 47$ innate immune checkpoint have been developed thus far including anti-CD47 and anti-SIRP $\alpha$ antibodies, and soluble SIRP $\alpha F c$, of which several are currently being evaluated in clinical trials. Of these, Hu5F9-G4, TTI-621 and ALX148 are furthest in development and have shown encouraging clinical data either alone or in combination with other agents [14, 20,21]. Nevertheless, the systemic use of CD47-targeting agents is thought to be hampered by the broad expression of CD47, which is manifested by severe depletion of RBCs and platelets, leading to acute anemia and thrombocytopenia in treated patients $[20,22]$ and requiring substantial amounts of agent to block CD47 on all immune cells (i.e. the "antigen sink"). Furthermore, CD47 is also a receptor for thrombospondin-1 (TSP1) [23] and blocking this interaction with anti-CD47 mAbs may have additional undesirable effects [24].

It may be anticipated that targeting of the SIRP $\alpha /$ CD47 axis with an anti-SIRP $\alpha$ blocking mAb [25] displays a favorable safety profile due to the more restricted expression of SIRP $\alpha$. SIRP $\alpha, \operatorname{SIRP} \beta$ and SIRP $\gamma$ belong to the class of paired receptors comprising separate genes that encode proteins with similar extracellular regions but different transmembrane or cytoplasmic regions. These different regions have opposite (i.e. inhibitory or activating) signaling potentials. Both SIRP $\alpha$ and SIRP $\beta$ are expressed in myeloid lineage cells, while SIRPy is expressed on T-cells, NK cells and NKT cells (Fig. 1a). SIRP $\gamma$ binds to CD47 albeit with a 10-fold weaker affinity than SIRPa [27], whereas no ligand has been described for SIRP $\beta$. The membrane distal extracellular Ig-like V-type $(\operatorname{IgV})$ domain of SIRP $\alpha$ is highly polymorphic and thus far 10 human SIRP $\alpha$ alleles have been described [26]. In the present study, we report the development of ADU-1805, a potentially best-in-class panallele SIRP $\alpha$ mAb that blocks the interaction of SIRP $\alpha$ with CD47 and lacks binding to SIRP $\beta 1$. Targeting SIRP $\alpha$ enhanced tumor cell uptake by macrophages and neutrophils at a similar rate as anti-CD47 mAbs. Finally, we present that SIRP $\alpha$ blockade functionally differentiates from anti-CD47 mAbs and shows improved safety in vitro and in vivo.

\section{Methods \\ Monoclonal antibody generation}

Full-length cDNA of human SIRPa variant 1 (hSIRPaV1) (GenBank accession: NM_001040022.1) and hSIRPaV2 (GenBank accession: D86043.1) were synthesized (GeneArt, Thermo Fisher Scientific), subcloned into the pCI-neo vector (Promega) and used to immunize mice. Hybridomas were generated as described previously [28]. Selected stable hybridomas were cultured in serum-free media for 7 days, supernatants were harvested, and antibodies were purified using MabSelect Sure Protein A resin (GE Healthcare). Antibody concentrations were quantified using spectrophotometry. The isotype of antibodies was established using mouse a monoclonal antibody isotyping kit (Bio-Rad Laboratories).

\section{Antibody sequencing and expression}

Antibody sequences were identified by DNA sequencing of the selected hybridomas (LakePharma). Antibody $\mathrm{VH}$ and VL genes were synthesized by GeneArt (Thermo Fisher Scientific), subcloned into the pcDNA3.1(+) vector (Thermo Fisher Scientific) and expressed in FreeStyle 293-F (Thermo Fisher Scientific) or ExpiCHO-S cells (Thermo Fisher Scientific). Transfected cells were cultured in serum-free media for 7 days and mAbs were purified using MabSelect Sure Protein A resin (GE Healthcare).

\section{Antibody humanization}

Humanization of the mouse anti-human SIRPa.40A $\mathrm{mAb}$ (hSIRP $\alpha .40 \mathrm{~A}$ ) was performed by grafting complementarity-determining region (CDR) residues onto a human germline framework [29]. Differences between mouse hSIRP $\alpha .40 \mathrm{~A}$ and the human 


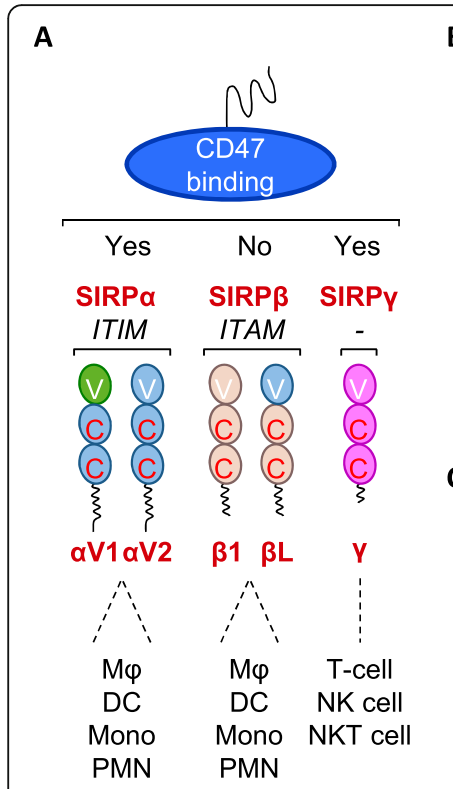

B

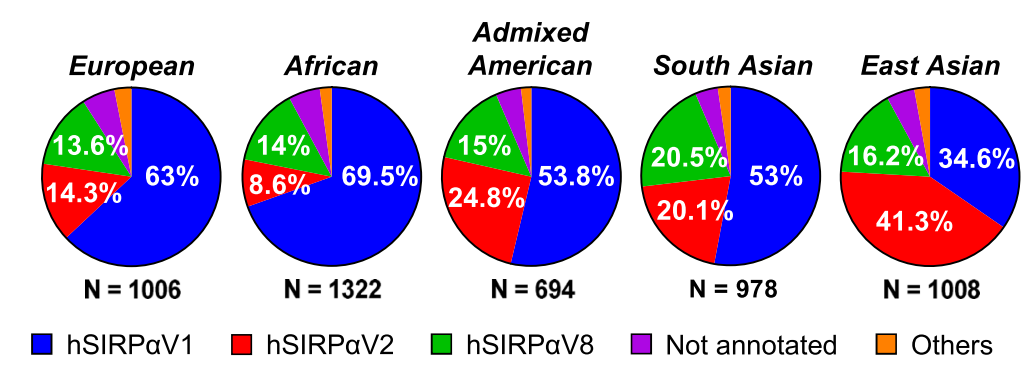

C

hSIRP $\boldsymbol{\alpha V 1}$ GVAGEEELQVIQPDKSVLVAAGETATLRCTATSLIPVGPIQWFRGAGPGRELIYNQKEGH hSIRP $\boldsymbol{\alpha V 2}$ GVAGEEELQVIQPDKSVSVAAGESAILHCTVTSLIPVGPIQWERGAGPARELIYNQKEGH hSIRP $\boldsymbol{\alpha V 8 ~ G V A G E E E L Q V I Q P D K S V L V A A G E T A T L R C T A T S L I P V G P I Q W F R G A G P A R E L I Y N Q K E G H ~}$

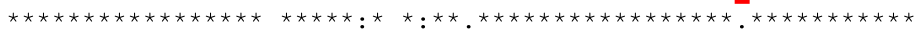

hSIRP $\alpha$ V1 FPRVTTVSDLTKRNNMDFSIRIGNITPADAGTYYCVKFRKGSPDDVEFKSGAGTELSVRA hSIRP $\alpha$ V2 FPRVTTVSESTKRENMDFSISISNITPADAGTYYCVKFRKGSP-DTEFKSGAGTELSVRA hSIRP $\alpha$ V8 FPRVTTVSESTKRENMDFSISISNITPADAGTYYCVKFRKGSP-DTEFKSGAGTELSVRA

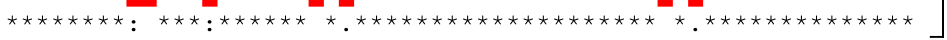

Fig. 1 SIRPaV1, SIRPaV2, and SIRPaV8 are the main SIRPa variants in human. a The SIRP family of paired receptors comprises inhibitory (SIRPa), activating (SIRP $\beta$ ) and non-signaling (SIRPY) members. M $\varphi$, macrophage; DC, dendritic cell; Mono, monocyte; PMN, polymorphonuclear neutrophils; NK cell, natural killer cell; NKT cell, natural killer T-cell. b The human SIRPA reference allele hSIRPaV1 is dominant in Europeans (EUR), Africans (AFR), Ad Mixed American (AMR) and South Asians (SAS), whereas hSIRPaV2 dominates in East Asians (EAS). Indicated percentages specify the SIRPA allele frequency of hSIRPaV1, hSIRPaV2 and hSIRPaV8. Not annotated, frequency > 3; Others, frequency < 3. c Sequence alignment of hSIRPaV1, hSIRPaV2, and hSIRPaV8 proteins (derived from [26]) demonstrates the differences within the CD47-binding extracellular Ig-like V-type (IgV) domain framework residues were individually modeled by a homology model on basis of PDB ID 3UMT (light chain), PDB ID 1EHL (heavy chain) and PDB ID 3BGF (Fv) using Discovery Studio 4.5 (BIOVIA). Post-translational modification (PTM) motifs were removed where possible.

\section{Cell lines and cell culture}

The BJAB (DSMZ), Raji (ECACC), THP-1 (ATCC), U937 (ATCC) and NK-92MI (ATCC) human cell lines, the IC-21 (ATCC) mouse cell line, and the CHO-K1 (ATCC) hamster cell line were cultured as recommended by the vendor. Cell lines were validated as Mycoplasma negative by Baseclear B.V. (Leiden) using a validated PCR test.

\section{Antibody affinity measurement}

A recombinant human SIRP $\alpha /$ His fusion protein (Sino Biological) was used for measuring monomeric binding affinity to hSIRPa.40A and derivatives thereof. Binding was assessed by bio-light interferometry (BLI) using amine coupling of mAbs to an AR2G biosensor (using standard NHS/EDC activation) followed by association/dissociation of recombinant $\mathrm{hSIRP} \alpha / \mathrm{His}$ and detection with the Octet RED96 (ForteBio).
SIRPa binding and blocking assay

For binding ELISA, CHO-K1 cells were transiently transfected with pCI-neo vectors encoding human, mouse or cynomolgus monkey (Macaca fascicularis) SIRP genes. Transfected cells were incubated with indicated mAbs, bound antibodies were detected using goat-anti-mouse IgG-HRP conjugate (Southern Biotech) or goat-anti-rat IgG-HRP conjugate (Jackson ImmunoResearch), visualized with TMB Stabilized Chromogen (Invitrogen), and detected using an EnVision (PerkinElmer).

Binding of anti-human SIRP $\alpha$ mAbs to human SIRP $\gamma$ was assessed by flow cytometry using NK-92MI cells. Antibodies were incubated at $4{ }^{\circ} \mathrm{C}$, stained with AF647labeled donkey anti-human IgG conjugate (Jackson ImmunoResearch), and analyzed by flow cytometry (FACSVerse, BD Biosciences).

SIRP $\alpha$ blocking ability was studied using THP-1 and U937 AML cell lines, where after incubation with FcR Blocking Reagent (Miltenyi Biotec) and indicated mAbs, DyLight 488-labeled recombinant human CD47/Fc-protein (R\&D Systems) was allowed to bind at $4{ }^{\circ} \mathrm{C}$ and analyzed by flow cytometry (FACSCanto II, BD Biosciences). SIRP $\alpha$ blocking ability on IC-21 cells was studied following incubation with indicated $\mathrm{mAbs}$ and recombinant mouse CD47/Fc-protein (R\&D Systems) at $37^{\circ} \mathrm{C}$, detection of bound CD47 protein using anti-human IgG-HRP conjugate (Jackson ImmunoResearch), which was visualized with TMB Stabilized 
Chromogen (Invitrogen) and detected using an EnVision (PerkinElmer).

\section{Flow cytometry}

Cells were phenotypically characterized using a FACSCanto II or FACSVerse flow cytometer with fluorochromeconjugated mAbs (Additional file 1: Table S1). Further details can be found in Additional file 2: Extended methods.

\section{Primary cell isolation}

Human blood was obtained from healthy volunteers who provided informed consent (Sanquin Bloodbank, Nijmegen, The Netherlands) and PBMCs were isolated by Ficoll-paque density gradient centrifugation. CD14+ monocytes were enriched ( $>70 \%$ purity) using RosetteSep Human Monocyte Enrichment Cocktail (Stemcell Technologies). NK cells were enriched (>90\% purity) using the untouched human NK Cell Isolation Kit (Miltenyi Biotec).

Granulocytes were isolated from erythrocyte-depleted whole blood upon incubation with $10 \mathrm{ng} / \mathrm{mL}$ recombinant human interferon- $\gamma$ (Immunotools) for $1 \mathrm{~h}$ at $37^{\circ} \mathrm{C}$ in $5 \% \mathrm{CO}_{2}$. Non-adherent blood cells were collected, and the percentage of granulocytes was determined by flow cytometry on the FACSCanto II (based on high FSC and SSC).

Similar procedures where applicable were also applied to EDTA whole blood obtained from healthy cynomolgus monkeys (Biomedical Primate Research Centre (BPRC), Rijswijk, The Netherlands).

\section{Neutrophil trogocytosis assay}

Human Burkitt's lymphoma BJAB cells were labeled with cell proliferation dye eFluor450 (Thermo Fisher Scientific). Labeled cells were mixed with assay medium (RPMI 1640 [Gibco], 10\% fetal bovine serum [Gibco] and $100 \mathrm{IU} / \mathrm{mL}$ penicillin-streptomycin [Gibco]), indicated $\mathrm{mAbs}$ and $0.1 \mu \mathrm{g} / \mathrm{mL}$ rituximab (anti-hCD20), and were then added to human granulocytes (at a ratio of 1:1 tumor cell per phagocyte) and incubated at $37{ }^{\circ} \mathrm{C}$ in $5 \%$ $\mathrm{CO}_{2}$ for $2 \mathrm{~h}$. Thereafter, $0.1 \mu \mathrm{g} / \mathrm{mL}$ propidium iodide was added to the mixture and trogocytosis (e.g. visualized as the appearance of eFluor450+ granulocytes) was assessed using the FACSVerse flow cytometer.

\section{Human macrophage generation and phagocytosis assay} Human macrophages were generated from CD14enriched monocytes cultured in CellCarrier 96-well flatbottom microplates (PerkinElmer) in medium (IMDM [Gibco], 8.5\% fetal bovine serum [Gibco] and $100 \mathrm{IU} / \mathrm{mL}$ penicillin-streptomycin [Gibco]) containing $50 \mathrm{ng} / \mathrm{mL}$ human monocyte colony stimulating factor (M-CSF) for 7 days at $37{ }^{\circ} \mathrm{C}$ in $5 \% \mathrm{CO}_{2}$. Raji cells labeled with eFluor450 were mixed with assay medium, indicated
mAbs (anti-CD47 antibodies were used at $66.7 \mathrm{nM}$ $(10 \mu \mathrm{g} / \mathrm{mL})$ and anti-SIRP $\alpha$ antibodies were titrated ranging from $66.7 \mathrm{nM}(10 \mu \mathrm{g} / \mathrm{mL})$ to $6.67 \mathrm{nM}(1 \mu \mathrm{g} / \mathrm{mL})$ and $0.67 \mathrm{nM}(0.1 \mu \mathrm{g} / \mathrm{mL}))$ and $1 \mu \mathrm{g} / \mathrm{mL}$ rituximab, and were then simultaneously added to human macrophages (at a ratio of 2.5:1 tumor cells per phagocyte) and incubated at $37^{\circ} \mathrm{C}$ in $5 \% \mathrm{CO}_{2}$ for $2 \mathrm{~h}$. After washing and fixation with $2 \%$ formaldehyde, cells were stained with biotinconjugated anti-human CD19 (eBioscience) for $1 \mathrm{~h}$ at room temperature (RT) and Alexa Fluor 488-conjugated streptavidin (Thermo Fisher Scientific). Nuclei were stained with DRAQ5 (Thermo Fisher Scientific) and phagocytosis was analyzed with the Operetta HighContent Imaging System (PerkinElmer). Data were processed and analyzed with Columbus V2.6 software (PerkinElmer). The phagocytosis of tumor cells was quantified counting at least 200 macrophages per sample and using an Uptake Index, as follows: (number of tumor cells inside macrophages/number of macrophages) $\times 100$.

\section{Antibody-dependent cell-mediated cytotoxicity (ADCC) assay}

CHO-K1.hSIRPaV1 cells were seeded in CellCarrier 384well flat-bottom microplates (PerkinElmer) and indicated mAbs were added in assay medium together with human NK cells (at an effector:target cell ratio of 1:5). After overnight incubation at $37^{\circ} \mathrm{C}$ in $5 \% \mathrm{CO}_{2}$ cells were washed, stained with Fixable Viability Dye eFluor660 (Thermo Fisher Scientific) and fixed in 5\% formalin for $10 \mathrm{~min}$ at RT. Fixed cells were washed and nuclei were stained with $1 \mu \mathrm{g} / \mathrm{mL}$ Hoechst 33342 (Life Technologies). Viable target cells were measured with the Operetta High-Content Imaging System and data were processed and analyzed with Columbus V2.6 software.

\section{Complement-dependent cytotoxicity (CDC) assay}

Human U-937 leukemia cells were labeled with CellTrace CFSE dye (Thermo Fisher Scientific). Labeled U937 cells were seeded in U-bottom 96-well plates, mixed with indicated $\mathrm{mAbs}$ and $20 \%$ human complement serum (Sigma-Aldrich) in assay medium, and incubated for $4 \mathrm{~h}$ at $37^{\circ} \mathrm{C}$ in $5 \% \mathrm{CO}_{2}$. Thereafter, $0.1 \mu \mathrm{g} / \mathrm{mL}$ DAPI was added to the mixture and $\mathrm{CDC}$ was assessed using the FACSVerse flow cytometer.

\section{Jurkat FcyRIIA-131H reporter assay}

Antibody-mediated activation of FcyRIIA-131H was established using CHO-K1.hSIRPaV1 cells and Jurkat Fc $\gamma$ RIIA-131H cells (Promega) at an effector:target cell ratio of $1: 2$, following the manufacturer's instructions.

\section{Allogeneic mixed lymphocyte reaction (MLR)}

To assess the allogeneic immune reaction, PBMCs from two human donors (referred to as the responder and 
stimulator (30 Gray (Gy) irradiated) were added together at a $\mathrm{R}: \mathrm{S}$ ratio of $1.5: 1$ ) in presence of mAbs and incubated at $37{ }^{\circ} \mathrm{C}$ in $5 \% \mathrm{CO}_{2}$ for 5 days. Supernatants were collected to quantify IFN $\gamma$ levels by ELISA (Thermo Fisher Scientific). The remaining cells were stained with fluorescent mAbs against CD3, CD4, CD8, CD19 and CD56 for $30 \mathrm{~min}$ at $4{ }^{\circ} \mathrm{C}$ and analyzed by flow cytometry.

\section{SEB-induced T-cell proliferation}

Human PBMCs were seeded in U-bottom 96-well plates, treated with $100 \mu \mathrm{g} / \mathrm{mL}$ of indicated mAbs and $1 \mu \mathrm{g} / \mathrm{mL}$ SEB (Sigma-Aldrich), and incubated for 3 days at $37^{\circ} \mathrm{C}$ in $5 \% \mathrm{CO}_{2}$. CD3 blast formation was assessed using the FACSVerse flow cytometer.

\section{Hemagglutination assay}

EDTA-treated human whole blood collected from healthy donor volunteers was washed with PBS, a $1 \%$ erythrocyte suspension $(\mathrm{v} / \mathrm{v})$ was prepared in PBS, and $50 \mu \mathrm{L}$ of the serially (2-fold) diluted mAbs or phytohemagglutinin (PHA-P; Sigma-Aldrich) were incubated with $50 \mu \mathrm{L}$ of the $1 \%$ erythrocyte suspension for $2 \mathrm{~h}$ at RT in clear 96-well U-bottom plates. Hemagglutination (visible as loss of RBC "button" formation) was quantitated using the ChemiDoc Touch Imaging System and analyzed with Image Lab 5.2.1 software (Bio-Rad Laboratories).

\section{Platelet aggregation and activation assay}

Blood was collected from healthy donor volunteers who provided informed consent (HaemoScan BV, Groningen, The Netherlands) and buffered with sodium citrate. To assess platelet aggregation (impedance method), blood was diluted with $0.9 \% \mathrm{NaCl}$ continuously mixed with a stir bar, impedance electrodes were fixed into the bloodcontaining tubes, and indicated mAbs, adenosine $5^{\prime}$-diphosphate sodium salt (ADP; Sigma-Aldrich) or vehicle (10 mM L-Histidine pH5.5 containing $0.1 \mathrm{M}$ sodium chloride) were added to the blood suspension. Aggregation was measured for $6 \mathrm{~min}$. The maximum slope of the aggregation curve for the first $3 \mathrm{~min}$ was determined from the recordings by " $\mathrm{R}$ : A language and environment for statistical computing" ( $\mathrm{R}$ Foundation for Statistical Computing). To assess platelet activation, the blood suspension was incubated with indicated mAbs, arachidonic acid (Sigma-Aldrich) or vehicle for $1 \mathrm{~h}$ at $37^{\circ} \mathrm{C}$. Samples were centrifuged and plasma was collected to execute the thromboxane B2 enzyme immunoassay (Cayman Chemical).

\section{Cytokine release assay}

Cytokine release was assessed on sodium heparinpreserved whole blood obtained from 24 healthy donor volunteers who provided informed consent (Sanquin
Bloodbank, Nijmegen, The Netherlands). Indicated mAbs were added to polystyrene U-bottom 96-well plates, whole blood was added, and plates were incubated overnight at $37^{\circ} \mathrm{C}$ in $5 \% \mathrm{CO}_{2}$. The cytokines IL-6, IL-8, TNF- $\alpha$, MCP-1, MIP- $1 \alpha$, and MIP- $1 \beta$ in the supernatants were detected using a custom human 6-plex assay kit (Thermo Fisher Scientific) and analyzed on the Bio-Plex MAGPIX multiplex reader (Bio-Rad Laboratories) equipped with Bio-Plex Manager 6.1 software (BioRad Laboratories).

\section{Mouse tumor xenograft model}

For tumor cell engraftment, $0.75 \times 10^{6}$ Daudi cells (diluted 1:1 with Matrigel) were injected subcutaneously into the left flank of approximately 11-week-old NOD.Cg-Prkd $c^{\text {scid }} I L 2 r g^{\mathrm{tm} 1 \mathrm{Wjl}} / \mathrm{SzJ}$ (NSG) mice, purchased from Charles River Laboratories (France). The animals were observed for tumor growth three times per week, starting 7 days after tumor cell injection. Treatment was initiated once tumors reached a size of 233 $\mathrm{mm}^{3} \pm 78 \mathrm{~mm}^{3}$. Mice were given intravenous injections of $50 \mu \mathrm{g}$ rituximab (anti-hCD20, human IgG1) or vehicle $(0.9 \% \mathrm{NaCl})$ three times per week. In two of the groups that received rituximab, mice were given intraperitoneal injections of $500 \mu \mathrm{g}$ anti-mSIRP $\alpha$ (clone .20A, mouse IgG1) three times per week, or alternatively mice were given daily intraperitoneal injections of $500 \mu \mathrm{g}$ antihCD47 (clone B6H12, mouse IgG1) for a duration of 4 weeks. Mice were monitored for morbidity and mortality daily. Tumor size was measured three times per week and mice were sacrificed when tumor size reached 2000 $\mathrm{mm}^{3}$. Tumor sizes were measured using a digital caliper and tumor volumes in $\mathrm{mm}^{3}$ calculated with a modified ellipsoid formula: $\mathrm{V}=\left(\right.$ length $\mathrm{x}$ width $\left.{ }^{2}\right) \times 0.28$. Animals were sacrificed when they reached humane endpoint or if they survived till day 34 after start of treatment.

\section{Toxicity study in NHPs}

A single-dose toxicity study was conducted at Covance Preclinical Services GmbH (Münster, Germany) according to a written study protocol and facility standard operating procedures in compliance with Institutional Animal Care and Use Committee (IACUC) criteria, national legal regulations on animal welfare, and accepted animal welfare standards. All animals were experimentally naive, purpose-bred cynomolgus monkeys originating from Asia. For the single-dose study, male $(n=4)$ and female $(n=4)$ animals were administered a single 15-min intravenous (i.v.) infusion of ADU-1805 (0.3, 3 or $30 \mathrm{mg} / \mathrm{kg})$ or vehicle control $(10 \mathrm{mM} \mathrm{L}$-Histidine $\mathrm{pH}$ 5.5 containing $0.1 \mathrm{M} \mathrm{NaCl}$ ). In-life evaluations included clinical observations, body weight, food consumption, standard neurologic and cardiovascular safety pharmacology evaluations, clinical pathology (serum chemistry, 
hematology, and coagulation), and toxicokinetics. To assess the pharmacokinetic properties of ADU-1805 in cynomolgus monkey serum, blood was drawn on $0,1,8$, and $24 \mathrm{~h}$, and $3,8,11,15,22,29,36,43,59$ days post single-dose ADU-1805. Fifty-nine days following the initial dose, the animals were necropsied and examined for gross observations, organ weights, and routine histopathologic evaluation was conducted on formalin-fixed paraffin embedded tissues collected at necropsy.

\section{Quantification and statistical analysis}

Data are reported as mean \pm standard deviation (SD) as specified. Statistical significance was determined by Student's t-test or one-way analysis of variance (ANOVA) as indicated, using GraphPad Prism version 8 (CA, USA). All Student's t-tests were two-sided under the assumption of equal variance between samples. All oneway ANOVA tests were corrected for multiple comparisons using statistical hypothesis testing. Differences were considered statistically significant if $p<0.05$.

\section{Results \\ Generation and characterization of a pan-SIRPa allele antibody}

An unbiased single-nucleotide polymorphism (SNP) analysis of human SIRP $\alpha$, based on data available at EnsEMBL (https://www.ensembl.org), revealed that SIRP $\alpha$ V1, SIRP $\alpha$ V2 and SIRP $\alpha$ V 8 are the most prominent haplotypes present among the human population (Fig. 1b). Of these, SIRP $\alpha$ V1 and SIRP $\alpha$ V2 differ the most in their IgV domain sequence (Fig. 1c). While SIRP $\alpha$ V1 is the most abundant allele among European, Admixed American and African populations, the SIRP $\alpha$ V2 allele is the most commonly found allele in East Asian population.

hSIRPa.40A was generated and identified as an antibody that demonstrated potent pan-allele SIRP $\alpha$ binding (i.e. binding human SIRP $\alpha$ V1, SIRP $\alpha$ V2 and SIRP $\alpha$ V8) and lacked appreciable SIRP $\beta 1$ binding (Fig. 2a). In contrast, the KWAR23 antibody binds to all SIRP $\alpha$ alleles and also the SIRP $\beta 1$ activating receptor. hSIRP $\alpha .40 \mathrm{~A}$ and KWAR23 both bind human SIRP $\beta L$ [31] and SIRP $\gamma$. hSIRP $\alpha .40 \mathrm{~A}$ showed potent antagonism of the two most prevalent SIRP $\alpha$ alleles (e.g. SIRP $\alpha$ V1 and SIRP $\alpha$ V2), as determined by blockade of CD47 binding to U-937 and THP-1 AML cell lines that express SIRP $\alpha$ V1 (data not shown) and SIRP $\alpha$ V2 [32], respectively (Fig. 2b).

The functional activity of hSIRPa.40A was assessed in vitro using a macrophage-based phagocytosis assay (. $3 \mathrm{a}, \mathrm{b})$. In this assay human peripheral blood-derived macrophages that endogenously express SIRP $\alpha$ are coincubated with Burkitt's lymphoma Raji cells (expressing both CD20 and CD47 (Additional file 3: Figure S1A, B)). In presence of rituximab, hSIRP $\alpha .40 \mathrm{~A}$ augmented tumor- cell uptake (calculated using the uptake index) of Raji cells by macrophages obtained from both SIRPA homozygous $(\mathrm{SIRP} \alpha \mathrm{V} 1 / \mathrm{SIRP} \alpha \mathrm{V} 1$ and SIRP $\alpha \mathrm{V} 2 / \mathrm{SIRP} \alpha \mathrm{V} 2)$ and heterozygous (SIRP $\alpha$ V1/SIRP $\alpha$ V2) individuals (Fig. 3c). The relevance of the unique binding profile of hSIRP $\alpha .40 \mathrm{~A}$ was illustrated by the anti-hSIRP $\alpha \mathrm{V} 1$ allele-specific mAb that only enhanced tumor cell phagocytosis by SIRP $\alpha$ V1/SIR$\mathrm{P} \alpha \mathrm{V} 1$ homozygous-derived macrophages while showing moderate or no phagocytosis by macrophages obtained from SIRP $\alpha$ V1/SIRP $\alpha$ V2 or SIRP $\alpha$ V2/SIRP $\alpha$ V2 individuals, respectively. Overall, this demonstrates the advantages of a pan-allele $\operatorname{SIRP} \alpha$ antibody to all homozygous and heterozygous SIRPA individuals.

To evaluate the therapeutic effect of SIRP $\alpha$ blockade in vivo we generated the anti-mouse $\operatorname{SIRP} \alpha$ surrogate mAb mSIRP $\alpha .20 A$ that specifically bound mouse SIRP $\alpha$, lacked cross-reactivity to SIRP $\beta$, and blocked CD47 binding, similar to anti-mSIRP $\alpha$ clone p84 (Additional file 4: Figure S2A, B) [33]. Surrogate mAb mSIRPa.20A bound to all mouse SIRPA alleles, including NOD SIRP $\alpha$ which is able to bind to human CD47 (Additional file 5: Table S2) [26]. The ability of mSIRPa.20A to eliminate subcutaneously engrafted Daudi Burkitt's lymphoma cells in NSG mice (that express the NOD SIRPA allele) was tested in combination with rituximab, analogous to the xenograft model described previously (Additional file 6: Figure S3A) [8]. Mice treated with the combination of $\operatorname{mSIRP} \alpha .20 \mathrm{~A}$ and rituximab showed decreased lymphoma burden and significantly prolonged survival compared to rituximab alone, confirming earlier observations (Additional file 6: Figure S3B, C) [25]. The blocking anti-hCD47 mAb B6H12 was taken along for comparison and showed complete inhibition of lymphoma engraftment when combined with rituximab. These results should be compared with caution as NSG mice lack an antigen sink for the anti-hCD47 antibody (e.g. anti-human CD47 does not bind to CD47 expressed on mouse cells).

\section{ADU-1805, humanized hSIRPa.40A}

To allow for human use, the mouse parental hSIRPa.40A antibody was humanized. First, a chimeric version of hSIRP $\alpha .40 \mathrm{~A}$ was generated by grafting the $\mathrm{VH}$ and VL sequences of hSIRP $\alpha .40 \mathrm{~A}$ onto the human constant domains of an IgG1, IgG2 or IgG4 heavy chain and human kappa light chain, respectively (Fig. 3d). Although the parental hSIRP $\alpha .40 \mathrm{~A}$ mAb augmented rituximab-induced phagocytosis of Raji cells by human macrophages similar to the anti-CD47 blocking mAb (AB6.12-IgG4PE), the activity of hSIRP $\alpha .40 \mathrm{~A}$ was completely abrogated when its $\mathrm{VH}$ and VL sequences were grafted onto a human IgG1 or IgG4 Fc backbone. In contrast, the human IgG2 chimeric variant of hSIRPa.40A retained the activity of the mouse parental mAb. 
A

Binding to human SIRP receptor family members
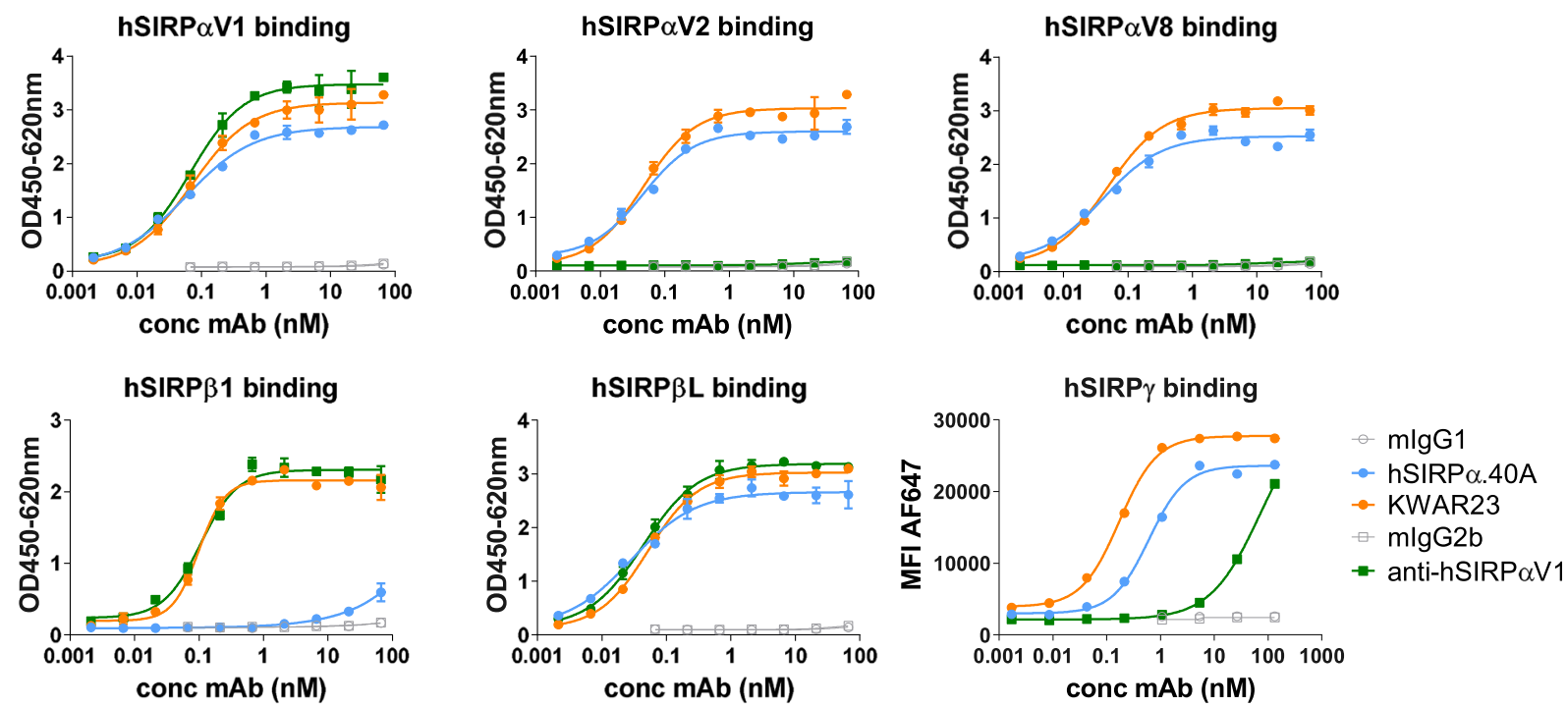

B

Blocking CD47 binding to human SIRPa
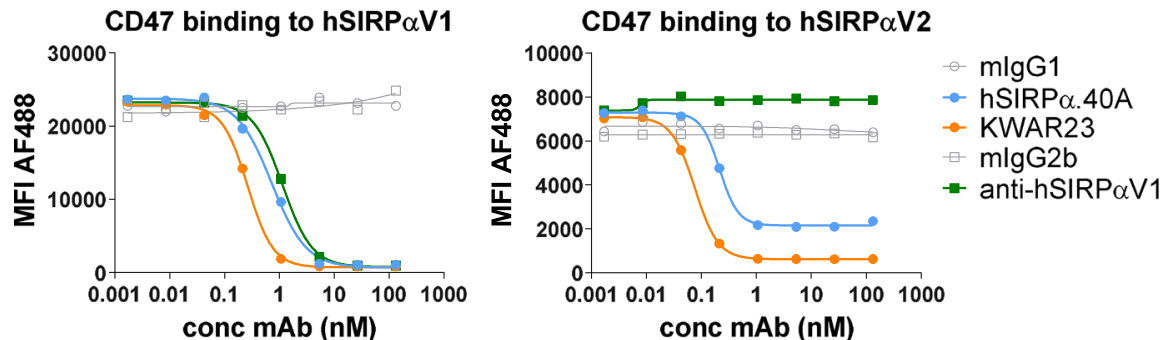

Fig. 2 hSIRPa.40A is a CD47 blocking antibody with a unique epitope. a hSIRPa.40A shows pan-allele anti-hSIRPa binding, cross-reacts with hSIRPy, and lacks appreciable hSIRPß1 binding, thereby differentiating from allele-specific (anti-hSIRPaV1) and pan-hSIRP antibodies (KWAR23 [30]). b hSIRPa.40A blocks CD47 binding to hSIRPaV1 and hSIRPaV2-expressing U-937 and THP-1 AML cell lines. (a, b: Mean \pm SD; representative of $n=$ 2 is shown)

We hypothesized that the mAb Fc of the chimeric hSIRP $\alpha .40 \mathrm{~A}$ interacted with FcyRs present on macrophages, which include at least the high affinity human IgG receptor FcyRI (CD64) and FcyRII (CD32) [34]. Indeed, human IgG1 and IgG4 variants of chimeric hSIRPa.40A bound to FcyRI while the human IgG2 variant did not (data not shown) [35]. In addition, human IgG1 and IgG4 Fc variants that minimize antibody Fc-FcyR interactions restored the enhancement of rituximab-mediated phagocytosis as compared to their wild-type counterparts (Additional file 7: Figure S4A), while similar mutations of the human IgG2 Fc did not further alter macrophage-dependent phagocytosis. Together, these data imply that an anti-SIRP $\alpha$ $\mathrm{mAb}$ should be grafted on a human IgG2 backbone to prevent engagement of $F c \gamma R$ on myeloid cells when bound to the antigen (creating a heterotrimeric interaction referred to as the 'scorpion effect' [36]) (Additional file 7: Figure S4B).

Subsequently, the mouse variable domains of hSIRPo.40A antibody were humanized by CDR grafting technology using matching human VH and VL frameworks [29], designated ADU-1805. ADU-1805 was confirmed to bind to monomeric human SIRP $\alpha$ antigen with a dissociation constant (KD) of $11 \times 10^{-9} \mathrm{M}$, similar to the parental and chimeric hSIRP $.40 \mathrm{~A}$ mAb (Table 1). Moreover, ADU-1805 bound to SIRPa expressed on human monocytes (EC50 $=0.23-1.57 \mathrm{nM})$ and neutrophils $(\mathrm{EC} 50=0.27-1.29 \mathrm{nM})$ but minimally bound to human lymphocytes $(\mathrm{EC} 50=0.94-7.33 \mathrm{nM})$, which are known to express SIRPy but not SIRP $\alpha$ [27] (Fig. 4a). Next, ADU-1805 was shown to enhance rituximab-induced phagocytosis, in a concentration-dependent manner, by human macrophages obtained from different human 
A

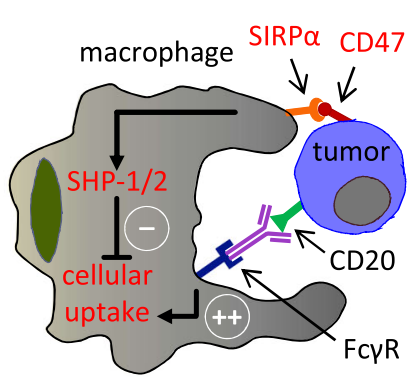

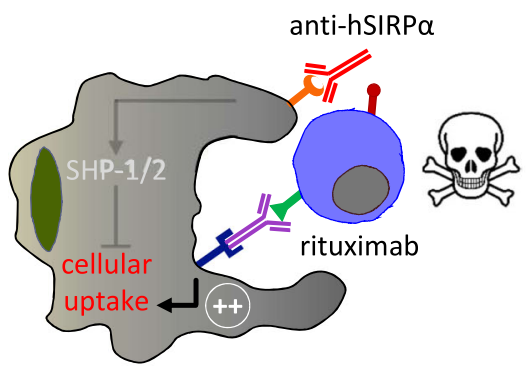

B

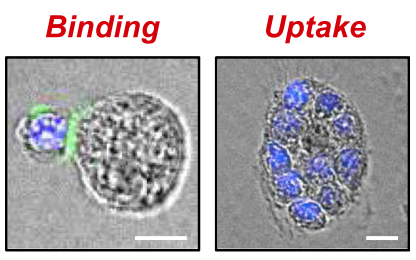

M $\varphi$ Tumor Ag Tumor cell

C

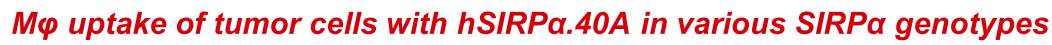

hSIRP $\alpha$ V1 homozygous

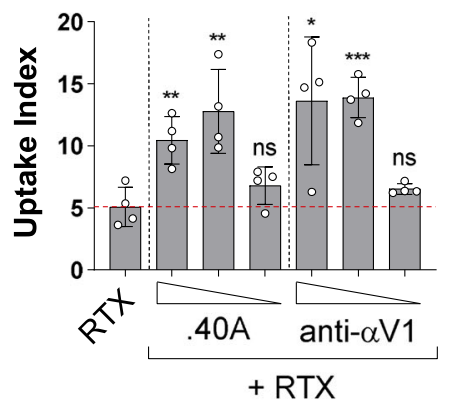

hSIRPoV2 homozygous

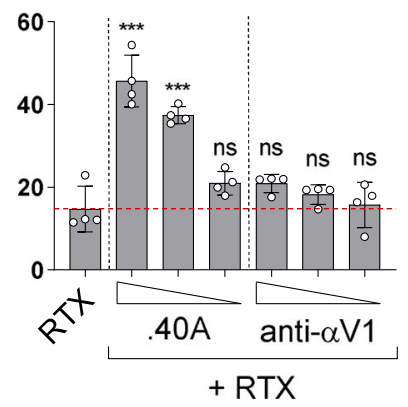

hSIRP $\alpha$ V1/V2 heterozygous

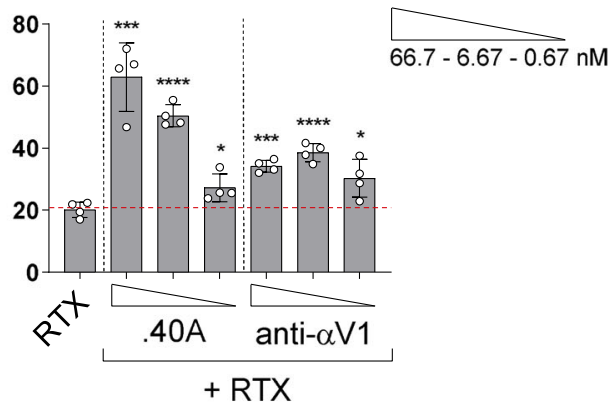

D

M $\varphi$ uptake of tumor cells with hSIRPa.40A and chimeric antibody variants
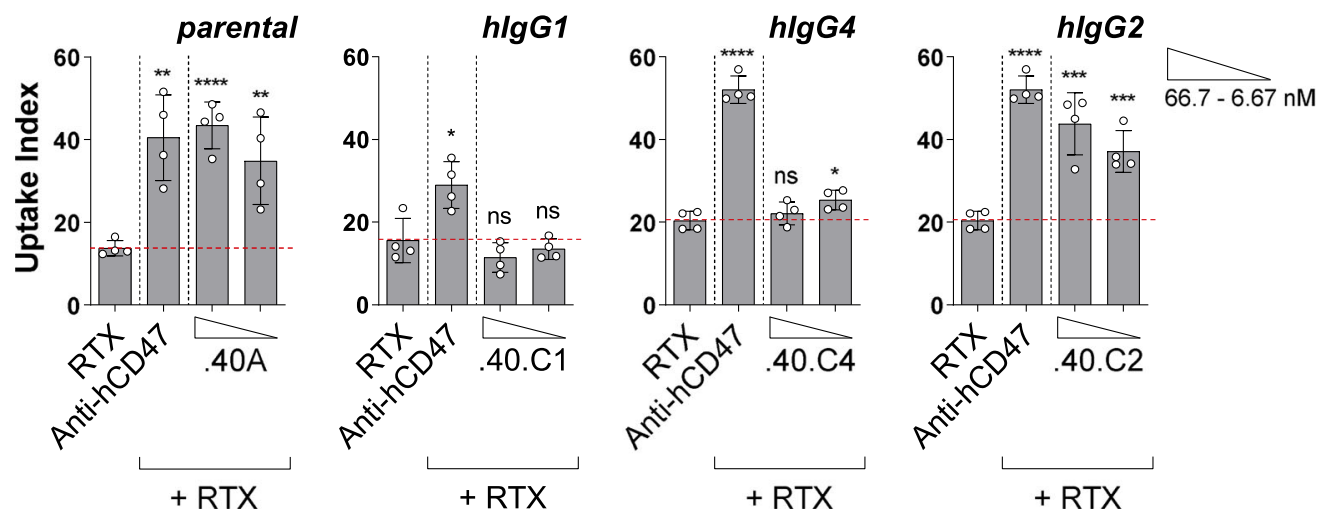

Fig. 3 hSIRPa.40A promotes tumor cell uptake in all SIRPA genotypes. a Illustration of tumor cell uptake by human macrophages upon engagement of FcyR and blockade of the SIRPa/CD47 axis. b Picture showing a human macrophage binding to a Raji cell opsonized with anti-tumor antibodies (in green; left) resulting in tumor cell uptake (right). Scale bar, $10 \mu \mathrm{m}$. c hSIRPa.40A promotes rituximab (RTX)-mediated macrophage tumor cell uptake in both homozygous and heterozygous SIRPA genotypes. (Mean \pm SD; representative of $n=2$ (hSIRPaV1), 4 (hSIRPaV1/N2) or 6 (hSIRPaV2) donors is shown). $\mathbf{d}$ Chimeric hSIRPa.40A promotes optimal macrophage-mediated tumor cell uptake on a human lgG2 (.40.C2) but not on a lgG1 (.40.C1) or $\operatorname{lgG4}$ (.40.C4) Fc backbone. (Mean \pm SD; representative of $n=2$ is shown). Data were analyzed by unpaired two-sided Student's t-test. The asterisks (*) indicate statistical differences compared to the RTX control group: ${ }^{*} p<0.05,{ }^{* *} p<0.01,{ }^{* * *} p<0.001,{ }^{* * *} p<0.0001$; ns, not significant

Table 1 hSIRPaV1 binding affinities of parental, chimeric, and humanized hSIRPa.40A variants measured on Octet AR2G biosensor. (Values represent Mean $\pm \mathrm{SD} ; n=2-4$ repeats)

\begin{tabular}{llll}
\hline Antibody & $\mathrm{KD}(\mathrm{M})$ & $\mathrm{ka}(1 / \mathrm{Ms})$ & $\mathrm{kdis}(1 / \mathrm{s})$ \\
\hline hSIRPa.40A & $12.1 \mathrm{E}-09 \pm 3.7 \mathrm{E}-09$ & $4.4 \mathrm{E}+05 \pm 1.1 \mathrm{E}+05$ & $5.6 \mathrm{E}-03 \pm 3.0 \mathrm{E}-03$ \\
hSIRPa.40.C2 & $15.4 \mathrm{E}-09 \pm 8.5 \mathrm{E}-11$ & $4.4 \mathrm{E}+05 \pm 9.7 \mathrm{E}+04$ & $6.8 \mathrm{E}-03 \pm 1.5 \mathrm{E}-03$ \\
ADU-1805 & $11.0 \mathrm{E}-09 \pm 1.85 \mathrm{E}-09$ & $3.4 \mathrm{E}+05 \pm 8.7 \mathrm{E}+04$ & $3.8 \mathrm{E}-03 \pm 1.4 \mathrm{E}-03$ \\
\hline
\end{tabular}

individuals (Fig. 4b). Also, ADU-1805 was shown to enhance rituximab-mediated cell killing by neutrophils in a concentration-dependent manner, through a process called trogocytosis [37] (Fig. 4c, d).

\section{Differentiation between ADU-1805 and anti-CD47 agents}

The more restricted expression of SIRP $\alpha$ was hypothesized to allow SIRP $\alpha$-targeting antibodies to differentiate 


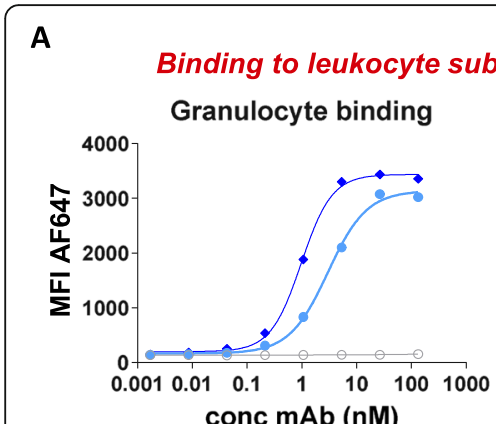

conc mAb (nM)
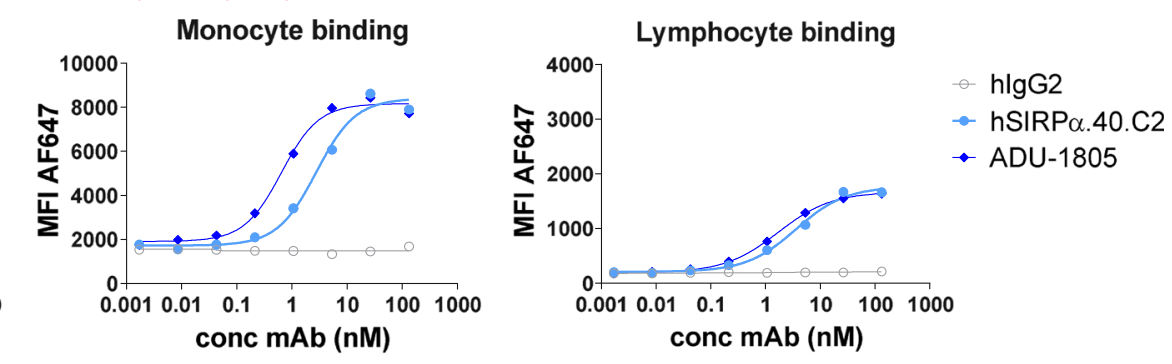

B
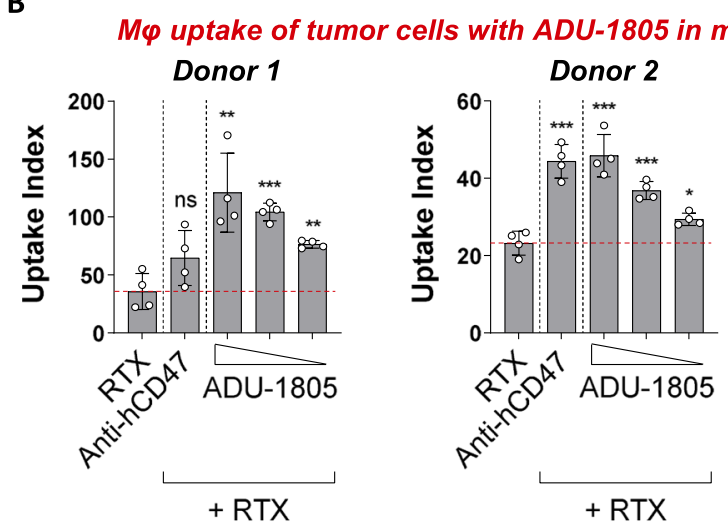

C
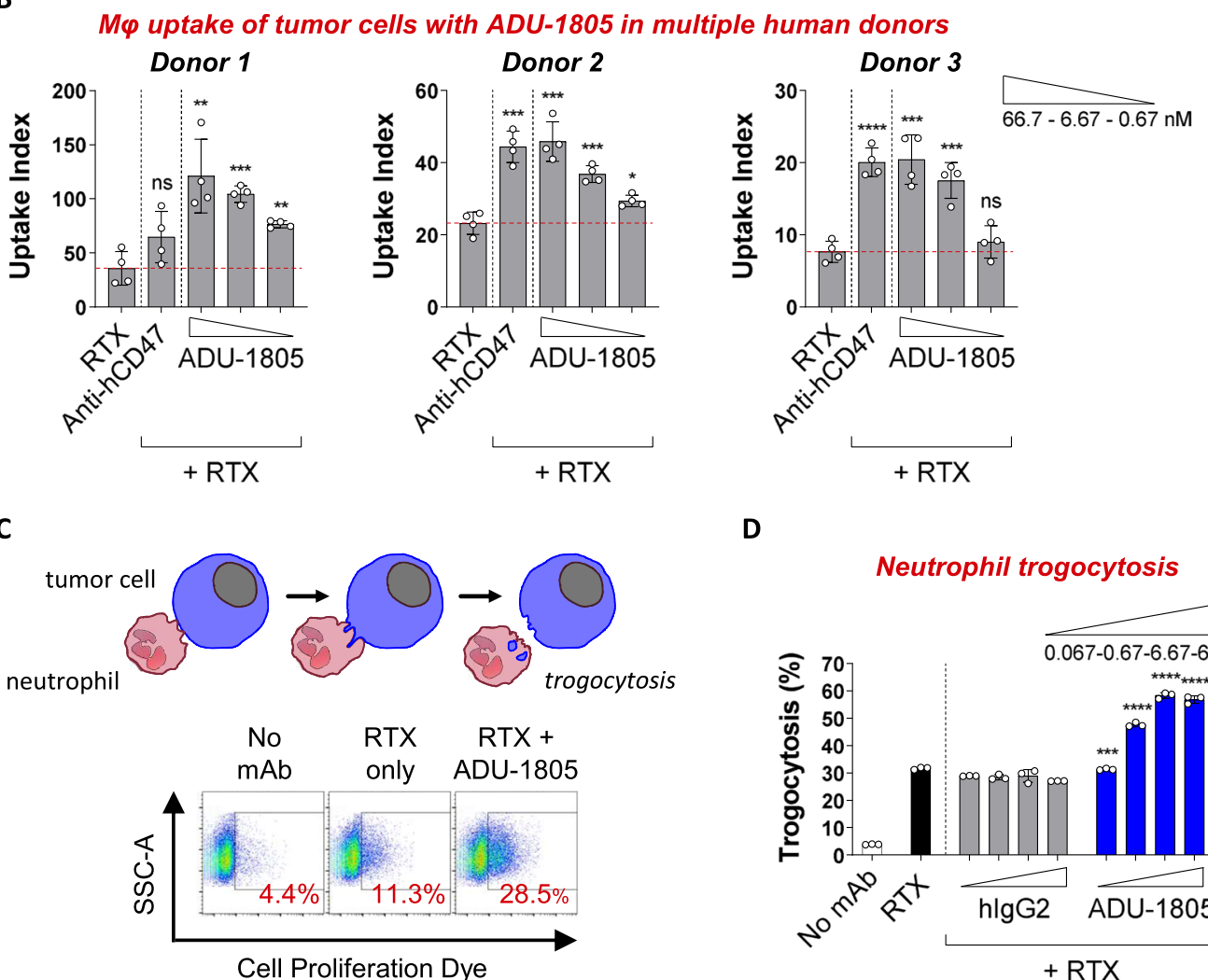

D

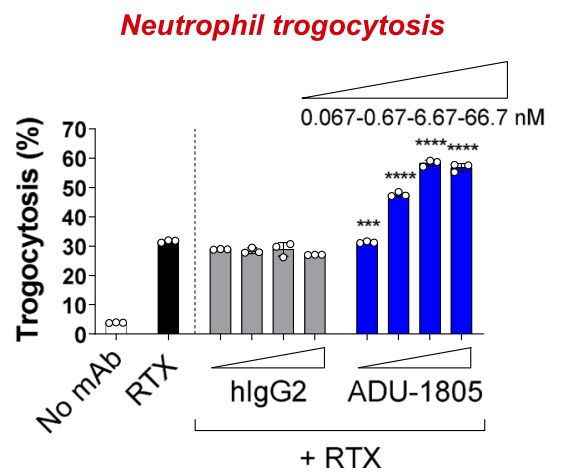

Fig. 4 Antibody humanization and characterization of ADU-1805. a Binding of ADU-1805 to erythrocyte-depleted whole blood. (Mean; representative of $n=6$ donors is shown). b ADU-1805 promotes macrophage-mediated tumor cell uptake, triggered by RTX. (Mean \pm SD; representative of $n=7$ donors is shown). Data were analyzed by unpaired two-sided Student's t-test. ${ }^{*}$ indicate statistical differences compared to the RTX control group: ${ }^{*} p<0.05,{ }^{* *} p<0.01,{ }^{* *} p<0.001,{ }^{* * *} p<0.0001$; ns, not significant. $\mathbf{c}$ The principle of tumor cell trogocytosis (trogo $=$ nibble), a process by which neutrophils take small bites from target cells. Flow cytometry analysis demonstrates that ADU-1805 enhances antitumor antibody-induced trogocytosis in a dose-dependent manner. $\mathbf{d}$ Quantification of tumor cell trogocytosis by human neutrophils. (Mean \pm SD; representative of $n=6$ is shown). Data were analyzed by unpaired two-sided Student's t-test. * indicate statistical differences compared to the respective isotype control group: ${ }^{* * *} p<0.001,{ }^{* * * *} p<0.0001$

from CD47-targeting agents. ADU-1805 lacked binding to human RBCs and platelets, and did not trigger hemagglutination, which is in line with its binding characteristics (Fig. 5a, b). Also, SIRP $\alpha$-targeting with the chimeric hSIRP $\alpha .40 \mathrm{~A} \mathrm{mAb}$ did not induce platelet aggregation or activation (Additional file 8: Figure S5). The restricted expression of SIRP $\alpha$ was further demonstrated by comparing the reactivity of ADU-1805 and anti-
CD47 towards human PBMCs. Anti-CD47 bound to all cell subsets present in the PBMC fraction (e.g. monocytes, B-cells, T-cells and NK cells), whereas ADU-1805 bound to monocytes and showed only minimal binding to T-cell subsets (Additional file 9: Figure S6). Altogether, based on the presented in vitro data, this confirms the hypothesis that ADU-1805 will show a biological activity profile differentiated from CD47- 

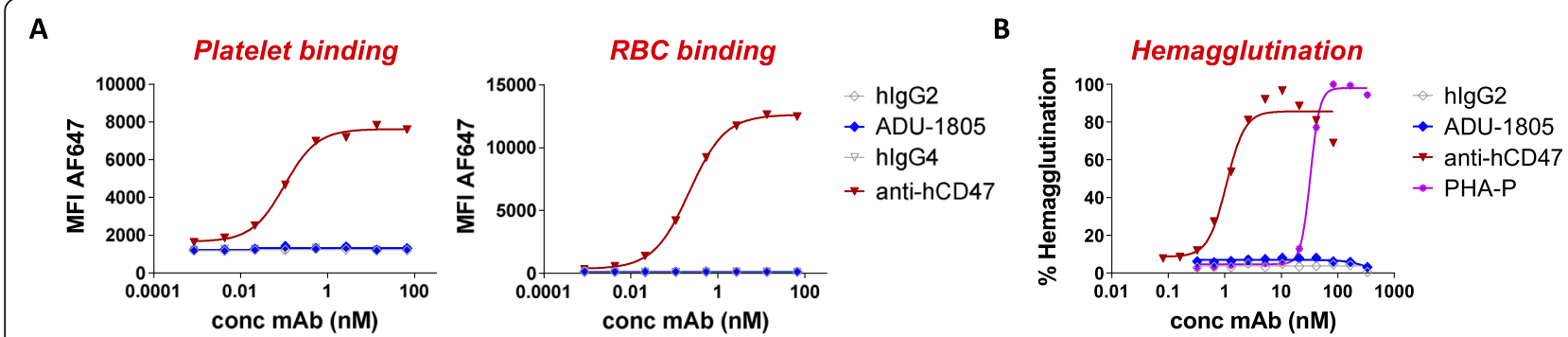

C

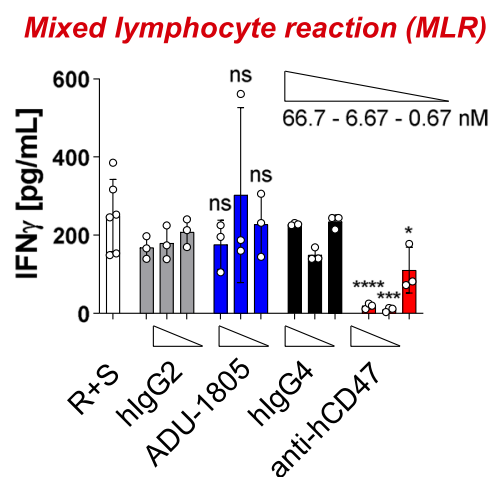

D

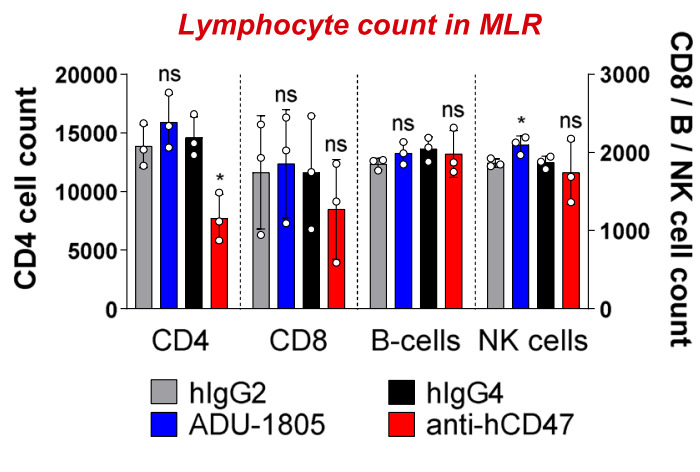

Fig. 5 ADU-1805 is anticipated to have a favorable safety profile over CD47-targeting agents. a In contrast to anti-CD47 (AB6.12-lgG4PE), ADU1805 does not bind to human platelets and RBCs, consistent with its binding specificities. (Mean; representative of $n=6$ is shown). b ADU-1805 does not trigger hemagglutination. Anti-CD47 clone B6H12 and phytohemagglutinin (PHA-P) serve as positive control. (Mean; representative of $n=12$ is shown). c ADU-1805 does not alter T-cell responses in an allogeneic MLR whereas anti-CD47 inhibits T-cell activation. The allogeneic immune reaction, when lymphocytes of two different donors are combined, results in T-cell activation. The resulting proliferation and/or production of cytokines were analyzed 5 days after start of culture. $\mathbf{d}$ Inhibition of T-cell activation by anti-CD47 coincides with a depletion of CD4+ T-cells. (c, d: Mean \pm SD; representative of $n=3$ donor combinations is shown). Data were analyzed by unpaired two-sided Student's t-test. ${ }^{*}$ indicate statistical differences compared to the respective isotype control group: ${ }^{*} p<0.05,{ }^{* * *} p<0.001,{ }^{* * *} p<0.0001$; ns, not significant

targeting agents by its more restrictive binding pattern (i.e. no antigen sink, minimal or no effect on RBCs and platelets).

A second potential differentiation was revealed by studying the effect of ADU-1805 on the role of CD47 in cell-cell adhesion through its interaction with SIRPY on neighboring T-cells [27]. Piccio et al. have demonstrated that blocking the SIRP $\gamma$-CD47 interaction with specific antibodies against either CD47 or SIRPY impaired T-cell activation by CD47+ antigen presenting cells [38]. Hence, we evaluated whether ADU-1805 affected T-cell activation in a PBMC-based allogeneic MLR. ADU-1805 did not alter the T-cell secretion of IFN $\gamma$ triggered by the allogeneic MLR, whereas anti-CD47 mAb treatment inhibited IFN $\gamma$ secretion (Fig. 5c). To understand the underlying cause of the reduced IFNY secretion as seen for CD47targeting mAbs, we characterized the immune cell subsets that were present at day 5 . While the representation of the various cell types remained unchanged in the ADU-1805 and isotype control antibody conditions, anti-CD47 treatment reduced the number of CD4+ T-cells in comparison to its respective isotype control antibody (Fig. 5d). Similarly, we found that anti-CD47 also reduced activation and blast formation of CD4+ T-cells in a SEB-induced T-cell proliferation assay (Additional file 10: Figure S7A, B), whereas ADU-1805 did not appear to affect T-cell activation and proliferation.

\section{Preliminary assessment of ADU-1805 safety and pharmacokinetics}

To complement the nonclinical antibody development, we demonstrated that ADU-1805 did not engage Fc $\gamma$ RIIA, nor did it induce ADCC via Fc $\gamma$ R-bearing NK cells (Additional file 11: Figure S8A, B). In addition, ADU-1805 did not induce CDC of the SIRP $\alpha$-expressing U-937 AML cell line, consistent with the observation that human IgG2 is a poor C1q binder [39] (Additional file 11: Figure S8C). Furthermore, ADU-1805 did not induce cytokine secretion in human whole blood, similar to the FDA-approved human IgG2 antibody panitumumab targeting epidermal growth factor receptor (EGFR) (Additional file 12: Figure S9).

To assess the differentiation of ADU-1805, safety and pharmacokinetics (PK) of ADU-1805 were established in vivo, in a single dose intravenous infusion in cynomolgus monkeys (Table 2). First, two putative variants, SIRP $\alpha$ V1 (NM_001284750.1) and SIRPaV2 (XP_ 015313155.1) were identified in cynomolgus monkey, 
Table 2 Study setup of the ADU-1805 non-GLP pilot toxicity study in 5-7 years old cynomolgus monkeys. A single dose of ADU-1805 or vehicle was administered i.v. for a duration of 15 min. Vehicle refers to the antibody formulation buffer: $10 \mathrm{mM} \mathrm{L-}$ Histidine pH 5.5 containing $0.1 \mathrm{M}$ sodium chloride

\begin{tabular}{llll}
\hline Group & Treatment & Dose & Animals \\
\hline 1 & Vehicle & - & 1 male $/ 1$ female \\
C2 & ADU-1805 & $0.3 \mathrm{mg} / \mathrm{kg}$ & 1 male $/ 1$ female \\
3 & ADU-1805 & $3 \mathrm{mg} / \mathrm{kg}$ & 1 male $/ 1$ female \\
4 & ADU-1805 & $30 \mathrm{mg} / \mathrm{kg}$ & 1 male $/ 1$ female \\
\hline
\end{tabular}

that share $99.2 \%$ sequence identity. These variants share a sequence identity of $>91 \%$ with human SIRP $\alpha$ V1 and SIRP $\alpha$ V2 and ADU-1805 bound to both cynomolgus variants with an EC50 $\leq 1 \mathrm{nM}$, similar to its binding affinity for human SIRP $\alpha$ (Additional file 13: Figure S10A). Furthermore, the ADU-1805 binding profile was comparable for human and cynomolgus monkey leukocytes (Additional file 13: Figure S10B).
Upon single-dose administration ADU-1805 measurements in serum followed by PK modelling demonstrated a dose proportional increase in exposure for the two higher dose levels with an estimated half-life of 1.866.41 days (Fig. 6a; Table 3). The administration of and exposure to ADU-1805 was well tolerated at all dose levels and no test-article related changes were observed. In contrast to the anti-CD47 mAb Hu5F9-G4 treatmentinduced acute anemia in cynomolgus monkeys [40], none of the ADU-1805 doses affected the hemoglobin levels after single-dose administration. This finding supports that targeting SIRP $\alpha$ via ADU-1805 may have a favorable safety profile compared to CD47-targeting agents (Fig. 6b).

\section{Discussion}

SIRP $\alpha-C D 47$ is considered an immune checkpoint (referred to as "don't-eat-me"), similar to the well-established T-cell immune checkpoints (i.e. PD-1, CTLA-4), but is predominantly acting on cells of the myeloid lineage. A

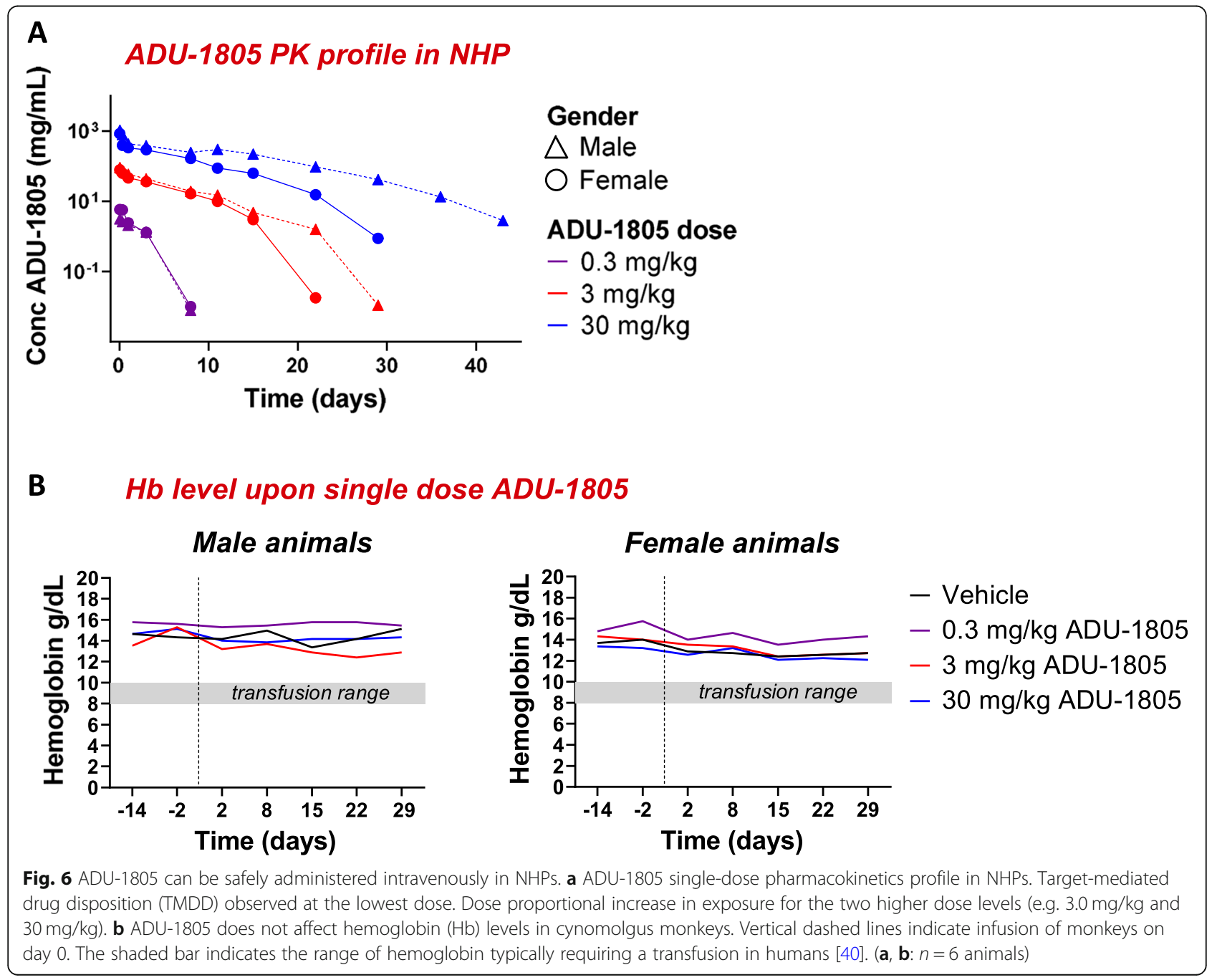


Table 3 The pharmacokinetic profile of ADU-1805 after a single dose exposure in NHPs

\begin{tabular}{lll}
\hline Dose & NCA half-life & Mid-range half-life \\
\hline $0.3 \mathrm{mg} / \mathrm{kg}$ & 0.88 days & 1.86 days \\
$3 \mathrm{mg} / \mathrm{kg}$ & 1.89 days & 3.93 days \\
$30 \mathrm{mg} / \mathrm{kg}$ & 2.95 days & 6.41 days \\
\hline
\end{tabular}

number of clinical trials are underway to evaluate SIRP $\alpha /$ CD47 blocking therapies [20-22], based on the notion that CD47 is overexpressed in various hematologic and solid tumors [6-11]. Blocking CD47 directly on tumor cells neutralizes the suppressive CD47 signal and activates macrophages through binding of the CD47-targeting agents to the FcyRs [41]. Also, macrophages recognize pro-phagocytic signals, such as calreticulin and phosphatidylserine that are induced on tumor cells as a result of therapies such as chemotherapy and radiotherapy [42], which in combination with inhibition of the SIRP $\alpha / C D 47$ axis are shown to promote tumor cell uptake. However, given the ubiquitous expression of CD47 on normal cells, on-target toxicity to healthy cells and a pronounced antigen sink present challenges with CD47-targeting approaches. Indeed, it has been observed that CD47targeting agents (i.e. Hu5F9-G4, TTI-621) induce acute anemia and thrombocytopenia in patients [20, 22, 43] which may also further depend on the Fc format. Recently, two clinical trials evaluating anti-CD47 mAbs were terminated: CC-90002 in AML and myelodysplastic syndromes (MDS) and SRF231 in patients with advanced solid tumors and hematological cancers. In contrast, the acute toxicity initially observed with Hu5F9-G4 was ultimately managed by adopting a dosing strategy that involved a priming (1 mg/kg priming on day 1 ) and maintenance phase $(30 \mathrm{mg} / \mathrm{kg}$ weekly for 3 doses and $30 \mathrm{mg} / \mathrm{kg}$ every other week thereafter) [40]. It remains to be seen whether this regimen will optimally induce anti-tumor activity. Next-generation variants of CD47 blocking agents such as ALX148 are being developed with reduced FcyR-binding properties [14]. Hence, ALX148 may induce reduced toxicity at the expense of single agent activity, similar to that seen with high-affinity SIRP $\alpha$ variants that lack an Fc chain [13]. Regardless, the broad expression of CD47 is thought to present an antigen sink on non-tumor tissue which remains a potential issue that could affect the bioavailability of the drug and thus its dosing strategy.

Due to its restricted tissue expression and predominant expression on cells of the myeloid lineage, direct targeting of SIRP $\alpha$ was hypothesized to overcome these CD47-targeting obstacles. Here, we describe a novel antagonistic pan-allele SIRP $\alpha$ antibody, hSIRP $\alpha .40 \mathrm{~A}$, and its humanized version ADU-1805. To assess the safety of SIRP $\alpha$-targeting, we conducted a single-dose toxicity study in cynomolgus monkeys and did not observe obvious signs of toxicity with ADU-1805, in part illustrated by the stable hemoglobin levels in blood, and the lack of acute anemia and thrombocytopenia. The PK modelling of ADU-1805 in cynomolgus monkeys led to an estimated ADU-1805 half-life of 1.86-6.41 days in blood serum which is consistent with currently approved IgG2 backbone-based mAbs [44]. While the current toxicity study does not rule out a potential SIRP $\alpha$ antigen sink for ADU-1805, it is the first to provide evidence that selective SIRP $\alpha$ targeting may be a safe alternative for CD47-targeting agents.

Besides SIRPa, innate immune cells also express other inhibitory receptors such as sialic-acid-binding Ig-like lectin 10 (Siglec-10). Siglec-10 binds to CD24, a ligand that, like CD47, is overexpressed in multiple human cancers. Recent data demonstrated the therapeutic potential of CD24 blockade with monoclonal antibodies which promoted the phagocytic clearance of CD24+ cancer cells in vitro and in vivo [45]. A potential advantage of targeting CD24 instead of CD47 is its absence on RBCs. However, CD24 is also present on B-cells, neutrophils, neurons and epithelial cells, and healthy B-cells are efficiently phagocytosed by macrophages upon anti-CD24 therapy. The expression of Siglec-10 is also not restricted to macrophages [46]. The above raises the concern of antigen sink and/or safety issues due to targeting of the Siglec-10-CD24 axis.

ADU-1805 is designed to bind to all described human SIRP $\alpha$ alleles and block CD47 binding without crossreacting to SIRP $\beta 1$, thereby differentiating it from other anti-SIRPa mAbs currently in preclinical development (i.e. BI 765063, KWAR23). In addition, ADU-1805 also binds to SIRPy expressed on T-cells, albeit with a 2.9fold reduced EC50 compared to SIRP $\alpha$, and thus may block the SIRPY-CD47 interaction. Targeting of this interaction using anti-CD47 mAbs or an anti-SIRPy $\mathrm{mAb}$, was previously shown to inhibit $\mathrm{T}$-cell proliferation in an allogeneic MLR [38, 47, 48]. We therefore assessed whether ADU-1805 alters T-cell activation using a similar assay. Despite minimal binding to $\mathrm{T}$ cells, ADU-1805 did not affect T-cell activation in an allogeneic MLR. ADU-1805 also did not change SEBinduced T-cell proliferation. In contrast, anti-CD47 $\mathrm{mAb}$ treatment had an inhibitory effect in both T-cell activation assays. We observed that anti-CD47 treatment ex vivo mainly decreased the number of (activated) CD4+ T-cells, while the effect on CD8+ T-cells was minimal. These results are in line with the defect of $\mathrm{CD} 47^{-1-} \mathrm{CD} 4+\mathrm{T}$-cells, that do respond to T-cell receptor (TCR)-induced activation, but exhibit a premature block in proliferation and survival [49]. It is unclear whether the reduced $\mathrm{T}$-cell responsiveness recorded for CD47-targeting agents translates to clinic administration. So, while encouraging early responses (i.e. tumor 
shrinkage by means of macrophage phagocytosis) with anti-CD47 have been observed in patients [20], longer follow-up is needed to address T-cell activation, since this may be required for durability of clinical responses.

We showed that FcyR binding of hSIRP $\alpha .40 \mathrm{~A}$ inhibits its functionality, which effect was absent by selection of a human IgG2 Fc-tail. Here, it is hypothesized that once anti-SIRP $\alpha$ binds to its target on Fc $\gamma$ R-bearing myeloid cells it may simultaneously co-engage activating or inhibitory Fc $\gamma$ Rs on the same cell, thereby creating a heterotrimeric interaction (Additional file 7: Figure S4B). This so-called scorpion effect [36] could modulate the therapeutic effect of an antibody. Similar observations were made for antibodies directed against colonystimulating factor 1 receptor (CSF1R), where for H27K15, a non-ligand competitive anti-CSF1R mAb [50], it was shown that the Fc region participates in its mode of action, suggestive of a similar scorpion effect.

Our data suggest that SIRP $\alpha$ targeting by ADU-1805 can activate myeloid cell types such as neutrophils and macrophages. The role of neutrophils and macrophages upon SIRP $\alpha$ blockade is further confirmed in xenograft mouse models that are deficient in T-cells, B-cells and NK cells $[25,30]$. Additional preclinical studies in syngeneic mouse models demonstrate that anti-SIRP $\alpha$ monotherapy changes the composition of immune cells in the tumor microenvironment with an apparent increase in the number of M1 type macrophages and a concomitant decrease in the M2 type [25]. TAMs are thought to differentiate predominantly into those of the M2 type, which display pro-tumorigenic activity and are implicated in the abrogation of anti-tumor immunity [51]. Repolarization of TAMs into M1 type macrophages may skew the microenvironment towards becoming more pro-inflammatory thereby promoting the anti-tumor immune response. Moreover, anti-SIRP $\alpha$ treatment led to a marked increase in the number of tumor-infiltrating $\mathrm{NK}$ cells and CD8+ T-cells, and antibody-mediated depletion of these cells decreased the inhibitory effect of SIRPa blockade on tumor formation [25]. Finally, anti-SIRP $\alpha \mathrm{mAbs}$ have the ability to enhance the activity of immune checkpoint inhibitors such as anti-PD-1 [25] and this has been confirmed in vivo with the CD47blocking molecule ALX148 in combination with anti-PD-1 or anti-PD-L1 therapy [14]. The enhanced anti-tumor response with agents blocking the SIRP $\alpha-C D 47$ interaction may arise from the activation of multiple DC subsets (i.e. shown by increased CD86 expression) that is seen within the spleen (data not shown) [14]. Consequently, blockade of the SIRP $\alpha / C D 47$ axis increases adaptive immune responses in combination with immune checkpoint inhibitors. Taken together, this suggests that agents targeting the SIRP $\alpha-C D 47$ innate immune checkpoint induce antitumor immunity by bridging innate and adaptive immune responses. Thus, we believe that blockade of the SIRP $\alpha$ /
CD47 axis using a pan-allele SIRP $\alpha$ mAb provides a novel approach to immunotherapy that may be applicable for a broad range of cancers. Nevertheless, it will be crucial to perform SIRP $\alpha$ SNP analysis and also biomarker analysis of treated patients in clinical trials. In the end, such retrospective studies could help to differentiate a predictive signature based on responders and non-responders.

\section{Conclusions}

ADU-1805 is a potentially best-in-class antagonistic SIRPo-targeting antibody with a unique epitope that encompasses pan-allele SIRPa binding. Unlike anti-CD47 mAbs, ADU-1805 does not trigger depletion of RBCs and platelets when tested at increasing dose levels in NHPs, supporting its favorable safety profile. The data presented herein support further development of ADU-1805.

\section{Supplementary information}

Supplementary information accompanies this paper at https://doi.org/10. 1186/s40425-019-0772-0.

\section{Additional file 1: Table S1. Antibodies used in this study.}

Additional file 2. Extended methods.

Additional file 3: Figure S1. CD20 and CD47 expression in human Burkitt's lymphoma cell lines.

Additional file 4: Figure S2. Specificity of anti-mouse SIRPa antibodies. Additional file 5: Table S2. Characteristics of the anti-mSIRPa antibodies described in this study. Mouse-rat chimeric mSIRPa.20A was generated by grafting the cDNA encoding the heavy chain and light chain variable domains onto the constant mouse $\lg G 1$ heavy chain and mouse kappa light chain.

Additional file 6 Figure S3. Anti-mSIRPa improves the efficacy of rituximab in NSG mice.

Additional file 7: Figure S4. Tumor cell uptake with anti-hSIRPa is most effective in absence of FcyR binding.

Additional file 8: Figure S5. Chimeric hSIRPa.40A does not impair platelet function.

Additional file 9: Figure S6. Anti-hSIRPa has a more selective binding profile as compared to anti-CD47.

Additional file 10: Figure S7. Anti-hSIRPa does not impair CD4+ or CD8+ T-cell proliferation.

Additional file 11: Figure S8. ADU-1805 is devoid of immune effector functions exemplified in complement and FcyR-dependent assays.

Additional file 12: Figure S9. ADU-1805 does not induce cytokine release in human whole blood.

Additional file 13: Figure S10. Cross-reactivity of ADU-1805 to cynomolgus monkey SIRPa.

\footnotetext{
Abbreviations

ADCC: Antibody-dependent cell-mediated cytotoxicity; ADCP: Antibodydependent cellular phagocytosis; BLI: Bio-light interferometry; CD: Cluster of differentiation; CDC: Complement-dependent cytotoxicity;

CDR: Complementarity-determining region; CELISA: Cell-based ELISA; CHO:

Chinese hamster ovary; CSF1R: Colony-stimulating factor 1 receptor;

Fc: Fragment crystallizable; FcyR: Fcy receptor; IgG: Immunoglobulin G;

IL: Interleukin; mAb: monoclonal antibody; M-CSF: Macrophage colonystimulating factor; MFI: Mean fluorescence intensity; MHC: Major

histocompatibility complex; MLR: Mixed lymphocyte reaction; NHP: Nonhuman primate; PBMC: Peripheral blood mononuclear cells; PD-

1: Programmed cell death-1; PD-L1: Programmed death-ligand 1;
} 
PK: Pharmacokinetics; PTM: Post-translational modification; RBC: Red blood cell; SEB: Staphylococcus enterotoxin B; SIRPa: Signal-regulatory protein a; TAM: Tumor-associated macrophage; VH: Variable domain heavy chain; VL: Variable domain light chain

\section{Acknowledgements}

We wish to thank Judith Stammen-Vogelzangs, Arne Bramer, Astrid Bertens, Bonny Lejeune, Erik van Buijtenen and Marija Dmitrijeva for skillful technical assistance during this study. We also thank Jeroen Elassaiss-Schaap and Anke Kip at PD-value B.V. for the pharmacokinetic data analysis of ADU-1805 in cynomolgus monkey blood serum.

\section{Authors' contributions}

$\mathrm{EV}, \mathrm{HvE}$ and JK wrote the manuscript. EV, HvE and PV contributed to the conception and design of experiments, and interpretation of data. EV, MP, DLH, SS, WJ, JR, IRB, GvdT, SVD, LD, MH and PvZ performed experiments and analyzed data. HvE, JK and AvE critically reviewed the manuscript. All authors read and approved the final version of the manuscript.

\section{Funding}

The study was sponsored by Aduro Biotech, Inc.

\section{Availability of data and materials}

All data generated that are relevant to the results presented in this article are included in this article and its supplementary files (Additional files). Other data that were not relevant for the results presented here are available from the corresponding author upon reasonable request.

\section{Ethics approval and consent to participate}

The welfare of the mice was maintained in accordance with the general principles governing the use of animals in experiments of the European Communities (Directive 2010/63/EU) and Dutch legislation (The revised Experiments on Animals Act, 2014). This included licensing of the project by the Central Committee on Animal Experimentation (project license 3721) and approval of the study by the Triskelion Animal Welfare Body (AWB number TRIS-200).

The NHP study was performed in compliance with the German Animal Welfare Act and was approved by the local IACUC (applied for by Covance Preclinical Services $\mathrm{GmbH}$ ). This study was performed in consideration of the DIRECTIVE 2010/63/EU OF THE EUROPEAN PARLIAMENT AND OF THE COUNCIL of 22 September 2010 on the protection of animals used for scientific purposes. In addition, this study was performed in consideration of the Commission Recommendation 2007/526/EC on guidelines for the accommodation and care of animals used for experimental and other scientific purposes (Appendix A of Convention ETS 123).

\section{Consent for publication}

Not applicable.

\section{Competing interests}

The authors have been or are employees of Aduro Biotech, Inc. and have stocks and/or stock options in Aduro Biotech, Inc. The authors do not have any financial competing interests. EV, PV, DLH, AvE and HvE have filed a patent application (WO2018/190719) that describes the invention of the antiSIRPa antibody hSIRPa.40A and its humanized variant ADU-1805. All the company-employed authors declare that their employment does not alter their adherence to the policies of Journal for Immunotherapy of Cancer.

\section{Received: 6 July 2019 Accepted: 5 October 2019}

\section{Published online: 04 December 2019}

\section{References}

1. Matlung HL, Szilagyi K, Barclay NA, van den Berg TK. The CD47-SIRPa signaling axis as an innate immune checkpoint in cancer. Immunol Rev. 2017;276(1):145-64.

2. Janssen WJ, McPhillips KA, Dickinson MG, Linderman DJ, Morimoto K, Xiao $Y Q$, et al. Surfactant proteins a and D suppress alveolar macrophage phagocytosis via interaction with SIRPa. Am J Respir Crit Care Med. 2008; 178(2):158-67.

3. Jiang $\mathrm{P}$, Lagenaur $\mathrm{CF}$, Narayanan $\mathrm{V}$. Integrin-associated protein is a ligand for the P84 neural adhesion molecule. J Biol Chem. 1999;274(2):559-62.
4. Oldenborg PA, Zheleznyak A, Fang YF, Lagenaur CF, Gresham HD, Lindberg FP. Role of CD47 as a marker of self on red blood cells. Science. 2000; 288(5473):2051-4.

5. Yamao T, Noguchi T, Takeuchi O, Nishiyama U, Morita H, Hagiwara T, et al. Negative regulation of platelet clearance and of the macrophage phagocytic response by the Transmembrane glycoprotein SHPS-1. J Biol Chem. 2002;277(42):39833-9.

6. Majeti R, Chao MP, Alizadeh AA, Pang WW, Jaiswal S, Gibbs KD, et al. CD47 is an adverse prognostic factor and therapeutic antibody target on human acute myeloid leukemia stem cells. Cell. 2009;138(2):286-99.

7. Poels LG, Peters D, van Megen Y, Vooijs GP, Verheyen RN, Willemen A, et al. Monoclonal antibody against human ovarian tumor-associated antigens. J Natl Cancer Inst. 1986;76(5):781-91.

8. Chao MP, Alizadeh AA, Tang C, Myklebust JH, Varghese B, Gill S, et al. AntiCD47 antibody synergizes with rituximab to promote phagocytosis and eradicate non-Hodgkin lymphoma. Cell. 2010;142(5):699-713.

9. Kim D, Wang J, Willingham SB, Martin R, Wernig G, Weissman IL. Anti-CD47 antibodies promote phagocytosis and inhibit the growth of human myeloma cells. Leukemia. 2012;26(12):2538-45.

10. Zhao H, Wang J, Kong X, Li E, Liu Y, Du X, et al. CD47 promotes tumor invasion and metastasis in non-small cell lung Cancer. Sci Rep. 2016;6:29719.

11. Willingham SB, Volkmer J-P, Gentles AJ, Sahoo D, Dalerba P, Mitra SS, et al. The CD47-signal regulatory protein alpha (SIRPa) interaction is a therapeutic target for human solid tumors. Proc Natl Acad Sci U S A. 2012;109(17):6662-7.

12. Zhao XW, van Beek EM, Schornagel K, der Maaden HV, Houdt MV, Otten $M A$, et al. CD47-signal regulatory protein-a (SIRPa) interactions form a barrier for antibody-mediated tumor cell destruction. Proc Natl Acad Sci. 2011;108(45):18342-7.

13. Weiskopf $K$, Ring AM, Ho CCM, Volkmer J-P, Levin AM, Volkmer AK, et al. Engineered SIRPa variants as immunotherapeutic adjuvants to anticancer antibodies. Science. 2013;341(6141):88-91.

14. Kauder SE, Kuo TC, Harrabi O, Chen A, Sangalang E, Doyle L, et al. ALX148 blocks CD47 and enhances innate and adaptive antitumor immunity with a favorable safety profile. PLoS One. 2018;13(8):e0201832.

15. Liu X, Pu Y, Cron K, Deng L, Kline J, Frazier WA, et al. CD47 blockade triggers T cell-mediated destruction of immunogenic tumors. Nat Med. 2015;21(10): 1209-15.

16. Soto-Pantoja DR, Terabe M, Ghosh A, Ridnour LA, DeGraff WG, Wink DA, et al. CD47 in the tumor microenvironment limits cooperation between antitumor T-cell immunity and radiotherapy. Cancer Res. 2014;74(23):6771-83.

17. Lo J, Lau EYT, Ching RHH, Cheng BYL, Ma MKF, Ng IOL, et al. Nuclear factor kappa B-mediated CD47 up-regulation promotes sorafenib resistance and its blockade synergizes the effect of sorafenib in hepatocellular carcinoma in mice. Hepatology. 2015;62(2):534-45.

18. Sockolosky JT, Dougan M, Ingram JR, Ho CCM, Kauke MJ, Almo SC, et al. Durable antitumor responses to CD47 blockade require adaptive immune stimulation. Proc Natl Acad Sci U S A. 2016:113:E2646-54.

19. Liu X, Liu L, Ren Z, Yang K, Xu H, Luan Y, et al. Dual targeting of innate and adaptive checkpoints on tumor cells limits immune evasion. Cell Rep. 2018; 24(8):2101-11.

20. Advani R, Flinn I, Popplewell L, Forero A, Bartlett NL, Ghosh N, et al. CD47 blockade by Hu5F9-G4 and rituximab in non-Hodgkin's lymphoma. N Engl J Med. 2018:379(18):1711-21.

21. Folkes AS, Feng M, Zain JM, Abdulla F, Rosen ST, Querfeld C. Targeting CD47 as a cancer therapeutic strategy: the cutaneous T-cell lymphoma experience. Curr Opin Oncol. 2018;30(5):332-7.

22. Sikic BI, Lakhani N, Patnaik A, Shah SA, Chandana SR, Rasco D, et al. First-inHuman, First-in-Class Phase I Trial of the Anti-CD47 Antibody Hu5F9-G4 in Patients With Advanced Cancers. J Clin Oncol. 2019;37:946-53 JCO.18.02018.

23. Gao AG, Lindberg FP, Dimitry JM, Brown EJ, Frazier WA. Thrombospondin modulates alpha $v$ beta 3 function through integrin-associated protein. J Cell Biol. 1996;135(2):533-44

24. Gao L, Chen K, Gao Q, Wang X, Sun J, Yang Y-G, et al. CD47 deficiency in tumor stroma promotes tumor progression by enhancing angiogenesis. Oncotarget. 2016;8(14):22406-13.

25. Yanagita T, Murata Y, Tanaka D, Motegi S-I, Arai E, Daniwijaya EW, et al. AntiSIRPa antibodies as a potential new tool for cancer immunotherapy. JCI Insight. 2017;2(1):e89140.

26. Takenaka K, Prasolava TK, Wang JCY, Mortin-Toth SM, Khalouei S, Gan Ol, et al. Polymorphism in Sirpa modulates engraftment of human hematopoietic stem cells. Nat Immunol. 2007;8(12):1313-23. 
27. Brooke G, Holbrook JD, Brown MH, Barclay AN. Human lymphocytes interact directly with CD47 through a novel member of the signal regulatory protein (SIRP) family. J Immunol. 2004;173(4):2562-70.

28. Guadagnoli M, Kimberley FC, Phan U, Cameron K, Vink PM, Rodermond H, et al. Development and characterization of APRIL antagonistic monoclonal antibodies for treatment of B-cell lymphomas. Blood. 2011;117(25):6856-65.

29. Queen C, Schneider WP, Selick HE, Payne PW, Landolfi NF, Duncan JF, et al. A humanized antibody that binds to the interleukin 2 receptor. Proc Natl Acad Sci. 1989;86(24):10029-33.

30. Ring NG, Herndler-Brandstetter D, Weiskopf K, Shan L, Volkmer J-P, George $\mathrm{BM}$, et al. Anti-SIRPa antibody immunotherapy enhances neutrophil and macrophage antitumor activity. Proc Natl Acad Sci. 2017;20:201710877.

31. Hatherley D, Graham SC, Turner J, Harlos K, Stuart DI, Barclay AN. Paired receptor specificity explained by structures of signal regulatory proteins alone and Complexed with CD47. Mol Cell. 2008:31(2):266-77.

32. Tsai RK, Rodriguez PL, Discher DE. Self inhibition of phagocytosis: the affinity of "marker of self" CD47 for SIRPalpha dictates potency of inhibition but only at low expression levels. Blood Cells Mol Dis. 2010;45(1):67-74.

33. Chuang W, Lagenaur CF. Central nervous system antigen P84 can serve as a substrate for neurite outgrowth. Dev Biol. 1990;137(2):219-32.

34. Bruhns $P$, Jönsson F. Mouse and human FcR effector functions. Immunol Rev. 2015;268(1):25-51.

35. Bruhns P, lannascoli B, England P, Mancardi DA, Fernandez N, Jorieux S, et al. Specificity and affinity of human Fcy receptors and their polymorphic variants for human lgG subclasses. Blood. 2009;113(16):3716-25.

36. Kurlander RJ. Blockade of fc receptor-mediated binding to U-937 cells by murine monoclonal antibodies directed against a variety of surface antigens. J Immunol. 1983;131(1):140-7.

37. Matlung HL, Babes L, Zhao XW, van Houdt M, Treffers LW, van Rees DJ, et al. Neutrophils Kill Antibody-Opsonized Cancer Cells by Trogoptosis. Cell Rep. 2018;23(13):3946-3959.e6.

38. Piccio L, Vermi W, Boles KS, Fuchs A, Strader CA, Facchetti F, et al. Adhesion of human $T$ cells to antigen-presenting cells through SIRP $\beta 2-C D 47$ interaction costimulates T-cell proliferation. Blood. 2005;105(6):2421-7.

39. Bindon $\mathrm{Cl}$, Hale $\mathrm{G}$, Brüggemann $\mathrm{M}$, Waldmann $\mathrm{H}$. Human monoclonal lgG isotypes differ in complement activating function at the level of C4 as well as C1q. J Exp Med. 1988;168(1):127-42.

40. Liu J, Wang L, Zhao F, Tseng S, Narayanan C, Shura L, et al. Pre-clinica development of a humanized anti-CD47 antibody with anti-Cancer therapeutic potential. PLoS One. 2015;10(9):e0137345

41. Pietsch EC, Dong J, Cardoso R, Zhang X, Chin D, Hawkins R, et al. Antileukemic activity and tolerability of anti-human CD47 monoclonal antibodies. Blood Cancer J. 2017;7(2):e536.

42. Chao MP, Jaiswal S, Weissman-Tsukamoto R, Alizadeh AA, Gentles AJ, Volkmer $J$, et al. Calreticulin is the dominant pro-phagocytic signal on multiple human cancers and is counterbalanced by CD47. Sci Transl Med. 2010;2(63):63ra94.

43. Ansell S, Chen RW, Flinn IW, Maris MB, O'Connor OA, Johnson LD, et al. A phase 1 study of TTI-621, a novel immune checkpoint inhibitor targeting CD47, in patients with relapsed or refractory hematologic malignancies. Blood. 2016;128(22):1812

44. Köck K, Pan WJ, Gow JM, Horner MJ, Gibbs JP, Colbert A, et al. Preclinical development of AMG 139, a human antibody specifically targeting $I \mathrm{~L}-23$. Br J Pharmacol. 2015;172(1):159-72.

45. Barkal AA, Brewer RE, Markovic M, Kowarsky M, Barkal SA, Zaro BW, et al. CD24 signalling through macrophage Siglec-10 is a target for cancer immunotherapy. Nature. 2019;572(7769):392-6.

46. Munday J, Sheena K, Jian NI, Cornish AL, Zhang JQ, Nicoll G, et al. Identification, characterization and leucocyte expression of Siglec-10, a novel human sialic acid-binding receptor. Biochem J. 2001;355(2):489-97.

47. Waclavicek M, Majdic O, Stulnig T, Berger M, Baumruker T, Knapp W, et al. T cell stimulation via CD47: agonistic and antagonistic effects of CD47 monoclonal antibody 1/1A4. J Immunol. 1997;159(11):5345-54.

48. Seiffert M, Brossart P, Cant C, Cella M, Colonna M, Brugger W, et al. Signalregulatory protein alpha (SIRPalpha) but not SIRPbeta is involved in T-cell activation, binds to CD47 with high affinity, and is expressed on immature CD34(+)CD38(-) hematopoietic cells. Blood. 2001;97(9):2741-9.

49. Azcutia V, Bassil R, Herter JM, Engelbertsen D, Newton G, Autio A, et al. Defects in CD4+ T cell LFA-1 integrin-dependent adhesion and proliferation protect Cd47-/- mice from EAE. J Leukoc Biol. 2017;101(2):493-505.

50. Haegel H, Thioudellet $\mathrm{C}$, Hallet $\mathrm{R}$, Geist M, Menguy $T$, Le Pogam F, et al. A unique anti-CD115 monoclonal antibody which inhibits osteolysis and skews human monocyte differentiation from M2-polarized macrophages toward dendritic cells. MAbs. 2013;5(5):736-47.

51. Brown JM, Recht $L$, Strober $S$. The promise of targeting macrophages in Cancer therapy. Clin Cancer Res. 2017;23(13):3241-50.

\section{Publisher's Note}

Springer Nature remains neutral with regard to jurisdictional claims in published maps and institutional affiliations.

Ready to submit your research? Choose BMC and benefit from:

- fast, convenient online submission

- thorough peer review by experienced researchers in your field

- rapid publication on acceptance

- support for research data, including large and complex data types

- gold Open Access which fosters wider collaboration and increased citations

- maximum visibility for your research: over $100 \mathrm{M}$ website views per year

At $\mathrm{BMC}$, research is always in progress.

Learn more biomedcentral.com/submissions 